\title{
Beyond hydrogen bonding: Recent trends in outer sphere interactions in transition metal catalysis
}

Received 00th January 20xx, Accepted 00th January $20 x x$ DOI: $10.1039 / x 0 x x 00000 x$

\author{
Jonathan Trouvé and Rafael Gramage-Doria*
}

\begin{abstract}
Homogeneous catalytic reactions are typically controlled by the stereoelectronic nature of the ligand(s) that bind to the metal(s). This so-called first coordination sphere effects have been taken into advantage for the efficient synthesis of fine chemicals relevant for industrial and academic laboratories since more than half a century. Such level of catalyst control has significantly upgraded in the last decades by mastering additional interactions beyond the first coordination sphere. This so-called second coordination sphere effects are mainly inspired by the action mode of nature's catalysts, enzymes, and, in general, rely on subtle hydrogen bonding for the exquisite control of activity and selectivity. In order to span the scope of this powerful strategy to challenges that cannot be solved by purely hydrogen bonding, a variety of less common interactions have been successfully introduced in the last few years for fine chemical synthesis. This review covers the latest and most exciting developments of this newly flourishing area with a particular focus to highlight how this type of interactions can be rationally implemented to control the reactivity in a remote fashion, that is, far away from the active site as enzymes also do.
\end{abstract}

\section{Introduction.}

The fundamental understanding of transition metal reactivity is at the core of the design of efficient homogeneous catalysts with relevance for small molecule synthesis. ${ }^{1}$ Consequently, new chemical reactions that are useful from drug discovery at small scale to implementation in large industrial plants have been disclosed. ${ }^{2}$ Furthermore, the last decades have witnessed tremendous advancements that established the importance of ligand design for controlling the reactivity outcome in homogeneous catalysis. ${ }^{3}$ As such, careful fine-tuning of the stereolectronic parameters of the ligand, that is the first coordination sphere, has direct consequences in catalyst performance (Figure 1a). ${ }^{4}$ For example, the P-M-P bite angle in diphosphane-ligated rhodium catalysts is an important parameter to control the linear:branched ratio of the aldehydes formed in the hydroformylation of terminal olefins. Analogously, the rate of reductive elimination in phosphaneligated palladium catalysts is largely determined by the electronic nature of the phosphorus centre. ${ }^{5}$

On the other hand, Nature's catalysts (enzymes) exploit a number of different strategies to control activity and selectivity. Most of them are based on dynamic and reversible events occurring in locations remote from the active site to adapt their spatial conformation to the substrate with the aim to precisely pre-organize it for reaching a given selectivity or to protect the active site in a hydrophobic pocket inside the

\footnotetext{
a. Univ Rennes, CNRS, ISCR-UMR6226, F-35000 Rennes, France, e-mail: rafael.gramage-doria@univ-rennes1.fr
}

whole protein. ${ }^{6}$ Chemists have forever been fascinated to mimic these features in homogeneous catalysis as it may lead to new reactivities in abiological systems. ${ }^{7-8}$ Initially, catalyst encapsulation via covalent chemistry or hydrophobic effects, ${ }^{9-}$ 13 and later, by means of supramolecular coordination chemistry, ${ }^{14-16}$ led to catalytic systems featuring enhanced catalyst stability together with new chemical trajectories. These strategies laid the foundation of supramolecular catalysis that are based on second coordination sphere effects aiming at overcoming the limitations and span the scope of traditional ligands. ${ }^{17-20}$

Alternatively, and much inspired from the hydrogen bonding in DNA base pairs, transition metal catalysts have incorporated hydrogen bonding recognition sites in the second coordination sphere (Figure 1b). Thereafter, the use of hydrogen bonding for the formation of self-assembled ligands as well as the positioning of substrates around the active site in a restricted conformation has been extensively explored with remarkable reactivity patterns. ${ }^{\mathbf{2 1 - 2 6}}$

In order to surpass this existing knowledge and tackle issues that cannot be addressed by the current approaches, it is important to rationally design catalytic systems with original action modes. ${ }^{27}$ In this context, exploiting interactions different than hydrogen bonding occurring far from the first coordination sphere of the transition metal catalyst is an attractive concept that has received increasing attention (Figure 1c). The most developed and studied interactions include dipole/dipole (those involving $\pi$ aromatic systems, halogen bonding), electrostatic (ion pairing, cation $\cdots$ crown ethers) and dative covalent bonds (Lewis pairing, metal $\cdots$ nitrogen bonding). The energy associated to these 
interactions, which can be as small as $1 \mathrm{kcal} / \mathrm{mol}$, are enough to stabilize unique intermediates in transition metal catalysis that allows access to otherwise unfavourable reaction pathways, thereby opening a new chemical space (Figure 1de). In this survey, a particular focus is devoted to those interactions taking place significantly far away from the first coordination sphere of the metal catalyst and that do not impart any stereoelectronic effect in the active site. However, their manifolds provide interesting entries into new ways of substrate pre-organization and customizing new self- assembled ligands. The present review covers the major advances accomplished in the last five years, ${ }^{24}$ in which the benefits of harnessing such uncommon interactions in transition metal catalysis in a remote fashion have been undoubtedly validated by means of extensive control experiments and/or substantial computational modelling. Examples involving secondary sphere interactions for promoting catalysis of small molecules $\left(\mathrm{H}_{2}, \mathrm{CO}_{2}, \mathrm{O}_{2}, \mathrm{~N}_{2} \mathrm{H}_{4}\right.$, etc. $)$, typically via electrocatalysis are beyond the scope of this review and they have been surveyed elsewhere. ${ }^{\mathbf{2 8 - 3 4}}$

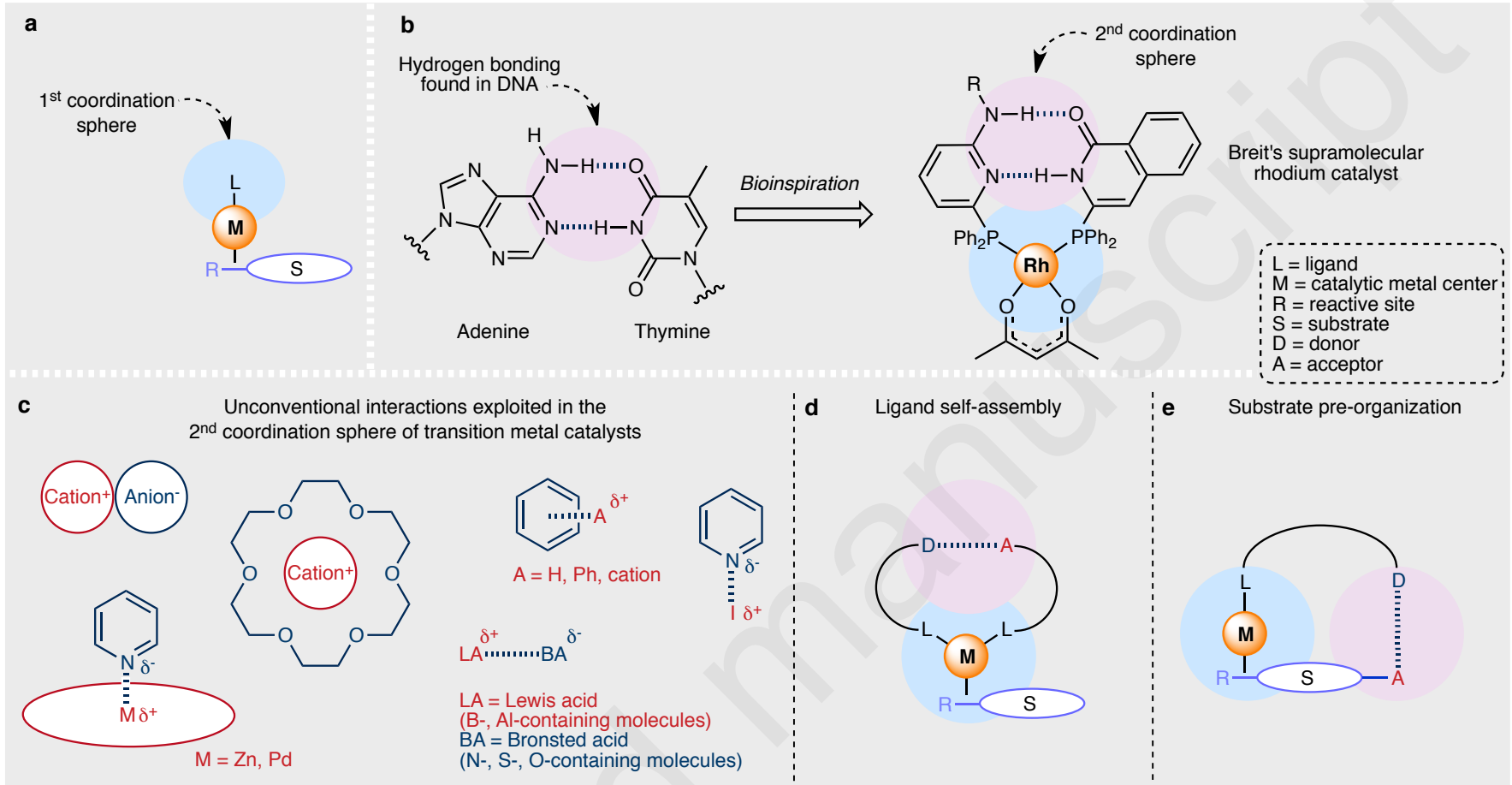

Figure 1. The relevance of first and second coordination sphere effects in transition metal catalysis. (a) Schematic representation of the first coordination sphere in a transition metal catalyst. (b) DNA-inspired hydrogen bonding features in the second coordination sphere of a transition metal catalyst to exert control in the reactivity. (c) Several examples of unconventional interactions that control the activity and selectivity in transition metal catalysts through the second coordination sphere. This type of interactions can be used for ligand self-assembly (d) or substrate pre-organization (e).

\section{2. lon-pairing.}

\subsection{Ion pairing for substrate pre-organization.}

Electrostatic interactions, a sub-class of non-covalent interactions, between cationic and anionic amino acid residues, cofactors and/or substrates are prevalent in enzymes for accessing unique reaction pathways due to their reversibility. ${ }^{35-36}$ However, implementation of such type of non-covalent interactions in transition metal catalysis requires to careful master them at the molecular level, especially in order to prevent undesired aggregated species. One strategy is based on the use of electrostatic interactions to pre-organize substrates in a precise conformation around the catalytically active metal site. ${ }^{37}$ In this context, the Ooi group showcased the unique potential of phosphine ligands covalently appended with chiral quaternary ammonium motifs for the palladiumcatalyzed construction of contiguous all-carbon quaternary stereocentres. $^{38}$ The asymmetric reactions studied were designed in a way that the remote chiral ammonium moiety from the ligand was ion-pairing with the in situ generated carbanion from the substrate in the intermediate prior to the cycloaddition to the palladium-coordinated $\pi$-allyl fragment (Scheme 1). In particular, this was applied to the highly enantio- and diastereoselective asymmetric [3+2] annulation of 5-vinyloxazolidinones and activated trisubstituted alkenes. Fine-tuning of the chiral ammonium-phosphine substituents in the ligands enabled a similar palladium-catalyzed reaction but using $N$-protected primary imines instead of alkenes. ${ }^{39}$ Ligands lacking the ammonium group led to poor reactivity and almost no selectivity. 

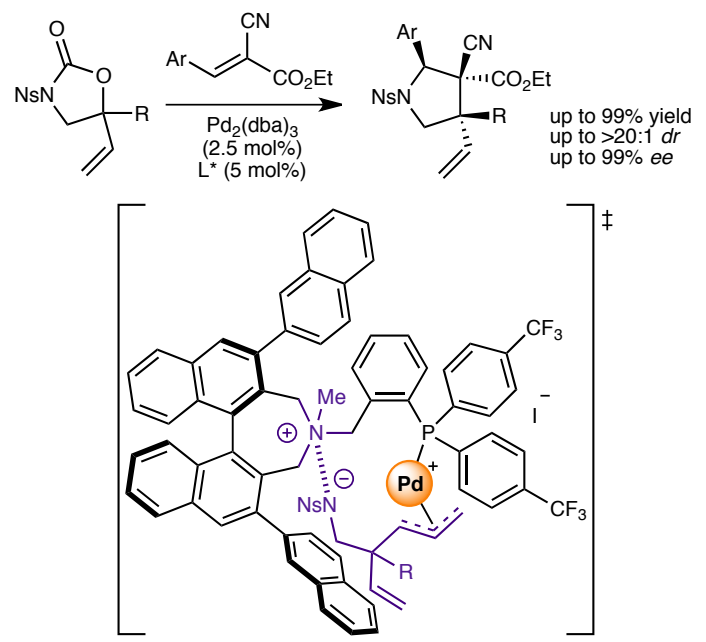

Scheme 1. An ammonium-containing phosphine ligand pre-organizes a substrate in a chiral pocket for highly asymmetric palladium catalyzed reactions.

The ammonium $\cdots$ anion pair interaction was utilized by the Zhang group for substrate pre-organization in the asymmetric rhodium-catalyzed hydrogenation of 1,1-disubstituted terminal olefins containing carboxylic acids. ${ }^{40-41}$ Planar- and Pchiral ferrocene-derived ligands comprising both a rhodiumcoordinating phosphane fragment and a tertiary amine unit were developed. The former served as an internal base for deprotonation of the carboxylic acid group from the substrate and further non-covalent binding site to the latter (Scheme 2). A broad scope was demonstrated and impressive turnover numbers (up to 20000) were reached with >99\% enantioselectivity. An extension to substrates containing phosphoric acids in place of carboxylic acids led to high enantioselectivities thanks to the ammonium...phosphate anion pair interaction in this case. ${ }^{42}$ The same group also reported ferrocene-derived phosphane ligands featuring a thiourea moiety that can undergo protonation under acidic conditions (i.e. $\mathrm{HCl}$ ). In combination with rhodium or iridium, a variety of asymmetric hydrogenations were reported with a chloride-assisted ion pairing with cationic substrates or cationic intermediates. ${ }^{43-46}$

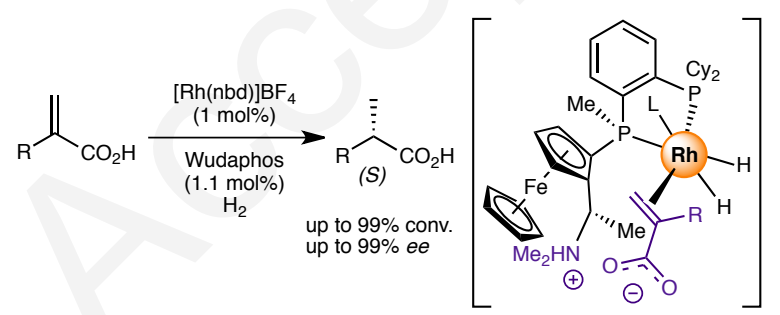

Scheme 2. The secondary ammonium $\cdots$ carboxylate interaction controls the asymmetric rhodium-catalyzed hydrogenation of carboxylic acid olefins.

The reversed possibility, which is the incorporation of cationic ammonium groups into substrates and anionic moieties in the ligand scaffold, was pioneered by the Phipps group. In order to tackle the very difficult regio-selective iridium-catalyzed $\mathrm{C}-\mathrm{H}$ bond borylation of arenes, a bipyridine derivative ligand containing a peripheral sulfonate motif was successfully applied with quaternized benzylamines and anilines as substrates, respectively. ${ }^{47}$ In this scenario, the cationic ammonium group from the substrate underwent ionpairing with the sulfonate group from the ligand enforcing the iridium-catalyzed $\mathrm{C}-\mathrm{H}$ bond borylation selectively to occur in the meta position of the arene ring (Scheme 3). The same ligand under comparable reaction conditions led to similar levels of meta-selectivity with substrates containing the ammonium group two or three bonds away from the arene ring. ${ }^{48}$ Similar observations were reported with substrates containing cationic phoshonium groups. ${ }^{49}$ In the absence of this outer sphere interaction, the selectivity drops to the expected statistical 1:1 mixture of meta and para-borylated products.

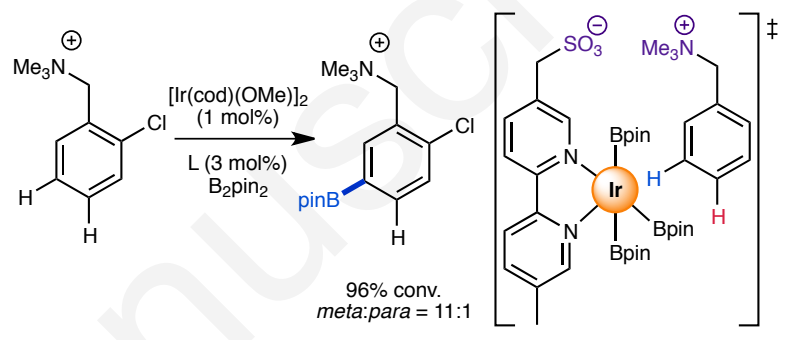

Scheme 3. The meta-selectivity in iridium-catalyzed $\mathrm{C}-\mathrm{H}$ bond borylation is achieved due to secondary sulfonate $\cdots$ ammonium interactions between the ligand and the substrate.

The same group devised a complementary strategy for para-selective $\mathrm{C}-\mathrm{H}$ bond borylations employing sulfonated substrates containing cationic tetrabutylammonium counterions and a simple bipyridine ligand. ${ }^{50}$ The perfect match between the sulfonate site and the bulky ammonium cation, both within the substrate, leaves exclusively the aromatic para-C-H bond accessible for functionalization (Scheme 4). Moreover, the regioselectivity outcome was finetuned by the size of the ammonium group. For instance, with a small tetramethylammonium anion a para:meta ratio of 3.5:1 was obtained, whereas a larger tetrahexylammonium anion led to an exceeding 13:1 ratio. This is a unique case in which remote ion-pairing controls regio-selectivity due to steric effects, although it cannot be strictly considered as an example of substrate-to-catalyst pre-organization as the previous examples. It is relevant to note that Smith, Malezcka, and coworkers described a very similar reaction design by remote ammonium $\cdots$ sulfonate anion pairing applied to alcoholderived sulfates and amine-derived sulfamates, respectively. ${ }^{\mathbf{5 1}}$ 


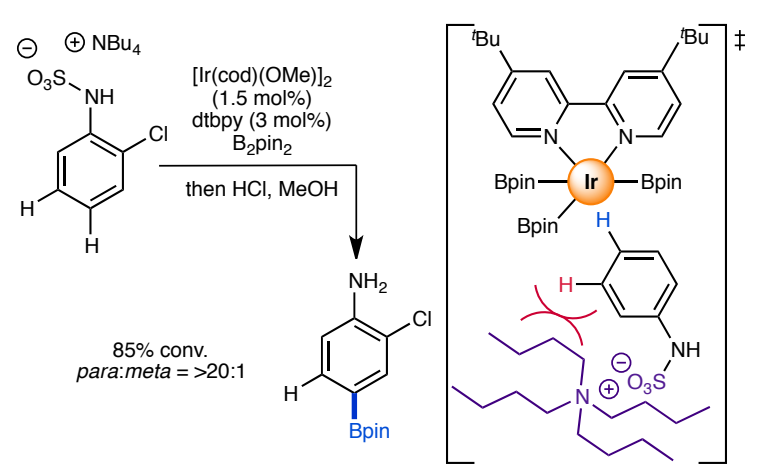

Scheme 4. The para-selectivity in iridium-catalyzed $\mathrm{C}-\mathrm{H}$ bond borylation is reached owing to secondary sulfonate $\cdots$ ammonium interactions between the substrate and an external ammonium salt

An increasing level of complexity was conceived by combining a threefold ion pairing as shown by the Phipps group. The design brings together both anionic catalyst and substrate with the help of an alkali metal cation. ${ }^{\mathbf{5 2}} \mathrm{A}$ Buchwald's type sulfonate-containing phosphine ligand enabled remote ion-pair interaction with the in situ deprotonated $\mathrm{N}$-triflate-containing substrates via additional $\mathrm{K}^{+}$ ion pairing, the latter originating from the base (Scheme 5). This strategy was successfully utilized in site-selective palladium-catalyzed cross-couplings of 3,4-dichloroarenes, in which the differentiation of reactivity for both chlorides is impossible with classical systems. Excellent levels of siteselectivity in favour of the reactivity at the meta chloride position were reached due to the high pre-organization encountered between the substrate and the catalyst. Consequently, the remaining chloride substituent can readily undergo post-functionalizations, thereby highlighting an excellent orthogonal reactivity. The same type of dichlorinated substrates were also studied in palladium-catalyzed $\mathrm{C}-\mathrm{H}$ bond arylation with fluorinated pyridine derivatives in which this threefold ion pairing was responsible for the observed meta

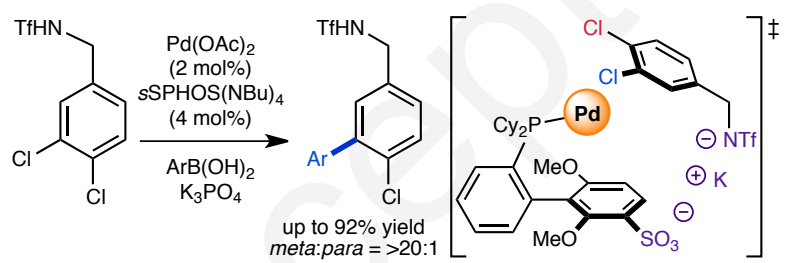

site-selectivity. $^{\mathbf{5 3}}$

Scheme 5. The palladium-catalyzed meta-selective arylation of 1,2dichlorobenzene derivatives was possible exploiting a threefold ionic network.

In subsequent studies, second coordination sphere electrostatic interactions involving potassium cations were exploited by the group of Chattopadhyay in regioselective iridium-catalyzed $\mathrm{C}-\mathrm{H}$ bond borylations using a bipyridine ligand containing a quinolone moiety. ${ }^{54}$ This functional group underwent tautomerization and deprotonation under catalytic conditions in order to recognize ester substrates via electrostatic interaction with the cationic alkali metals. Indeed, in the presence of catalytic amounts of a potassium source, the iridium-catalyzed $\mathrm{C}-\mathrm{H}$ bond borylation was found to be para-selective (Scheme 6). The same strategy applied to aromatic amides led to meta-selective borylated products, which was rationalized due to distorted $\mathrm{K}^{+} \cdots \mathrm{O}=\mathrm{C}$ non-covalent interactions or through $\mathrm{K}^{+} \cdots \pi$ amide non-covalent interactions. $^{\mathbf{5 5}}$ It is relevant to note that electrostatic interactions involving alkali cations $\left(\mathrm{Li}^{+}, \mathrm{Na}^{+}, \mathrm{K}^{+}, \mathrm{Cs}^{+}\right)$from (in)organic bases and anionic sites of substrates are known to decrease to some extent the key transition states energy according to theoretical calculations. Most of these types of interactions occur nearby to the first coordination sphere of the catalyst or they directly change the reactivity of the substrate, as such, they are typically postulated a posteriori due to the difficulty to anticipate the directionality of these interactions. $^{56-66}$

Scheme 6. An anionic ligand interacts with a neutral arene substrate

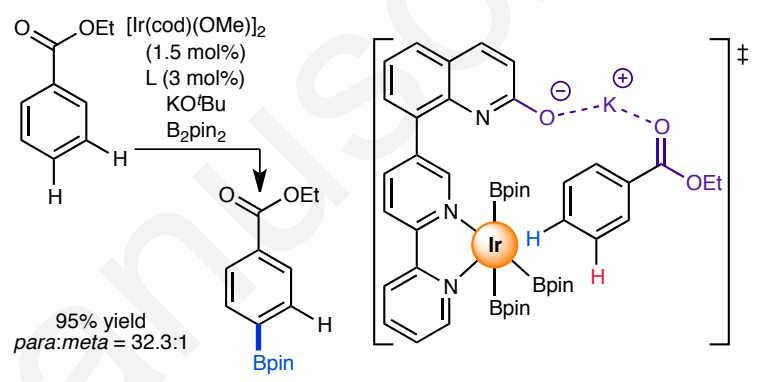

via $\mathrm{K}^{+}$...oxygen lone pair interactions, thus controlling the regioselectivity in iridium-catalyzed $\mathrm{C}-\mathrm{H}$ bond borylation.

\subsection{Ion pairing for catalyst (and substrate) self-assembly}

Besides the use of ion pairing for substrate pre-organization, it is also possible to exploit it for the self-assembly of catalysts. Following their pioneering contribution regarding ion-pair selfassembled ligands for asymmetric palladium catalysis, ${ }^{67}$ the Ooi group reported further applications of this design by combining achiral phosphine ligands appended with cationic ammonium groups and deprotonated chiral phosphoric acids. ${ }^{68}$ By these means, the control of the $E / Z$ selectivity and the enantioselectivity was achieved for the palladiumcatalyzed allylation of benzofuranones with 1,2-disubstituted allylic carbonates (Scheme 7). A clear advantage of this strategy is that there is no requirement to covalently introduce chiral elements in the phosphine ligand. In addition, owing to the straightforward in situ preparation of these supramolecular ligands, they were smartly used in a deconvolution strategy in which mixtures of ligands were employed for rapid searching of the optimal catalytic system. ${ }^{69}$ This was shown for the palladium-catalyzed asymmetric allylation of 3-benzylbenthiophenone derivatives, in which 12 chiral acids and 12 achiral phosphine ligands were used. Compared to the 144 experiments that would have been conducted individually, the best conditions (ee up to 94\%) were found with only 16 experiments applying this combinatorial screening. Further application to palladiumcatalyzed branched-selective decarboxylative allylations was also addressed using achiral anions. ${ }^{70}$ 

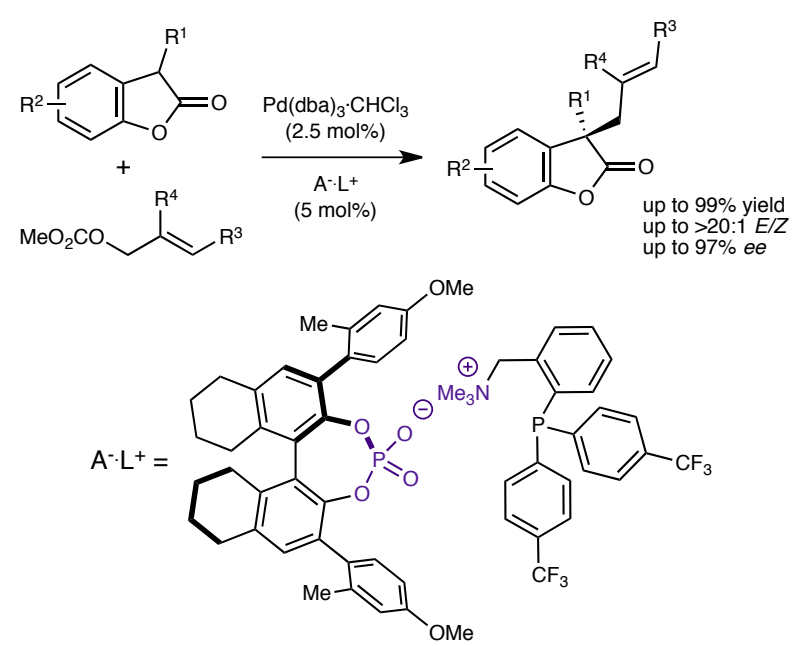

Scheme 7. A self-assembly ligand by secondary ammonium $\cdots$ phosphate interaction leads to highly asymmetric palladium-catalyzed transformation.

Recently, the Phipps group assessed a similar ion pair strategy applied to very challenging asymmetric iridiumcatalyzed $\mathrm{C}-\mathrm{H}$ bond borylation. ${ }^{71}$ They employed an anionic sulfonated bipyridine ligand combined with a chiral cation derived from dihydroquinine (Scheme 8). In addition, the sulfonate group in the ligand served as well for hydrogen bonding with the substrate to control the regioselectivity within the arene ring. $^{\mathbf{7 2}}$ In this manner, a large number of chiral-at-carbon and chiral-at-phosphorus compounds, respectively, were obtained with excellent enantioselectivies. The association constant for this type of assemblies was estimated to be $24 \mathrm{M}^{-1}$. This rather low value explains that small differences in the structure of both the ligands and the substrates lead to dramatic differences in the reactivity.

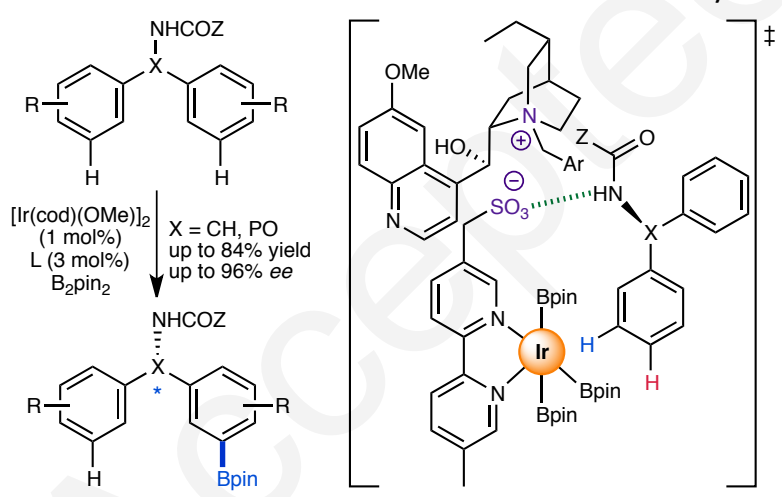

Scheme 8. A chiral cation self-assembles with an anionic catalyst resulting in iridium-catalyzed $\mathrm{C}-\mathrm{H}$ bond borylations with excellent enantioselectivity (green dashed lines indicate hydrogen bonding)

An interesting electrostatic interaction was rationalized for the outcome of the ruthenium-catalyzed crossdehydrogenative coupling of arene carboxylic acids by Baidya and co-workers. ${ }^{73}$ The role of DBU $(1,8-$ diazabicyclo[5.4.0] undec-7-ene) as the base was not to directly participate in the $\mathrm{C}-\mathrm{H}$ activation event but rather to handle the carboxylate anion via ion-pairing prior to the concerted metalation deprotonation step (Scheme 9). Consequently, the energy required to access the key transition state was significantly reduced by $>50 \mathrm{kcal} / \mathrm{mol}$ with respect to that required without the DBU remote ion pairing effect. With other bases, the reactivity of the catalyst was suppressed.

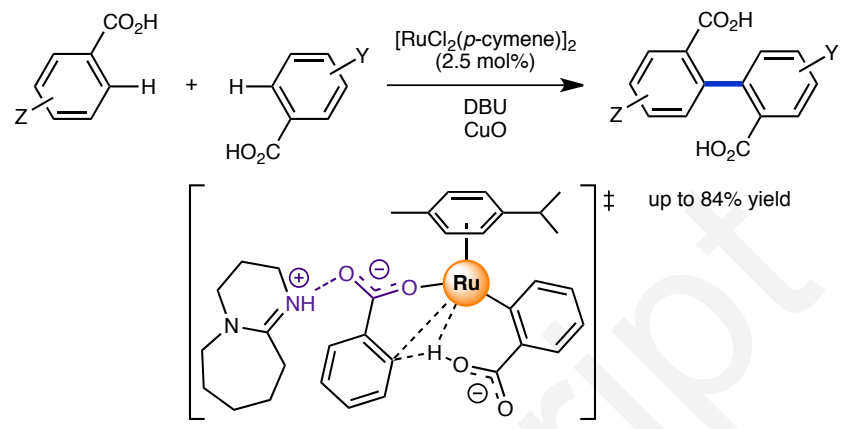

Scheme 9. Ruthenium-catalyzed cross-dehydrogenative coupling of arene carboxylic acids enabled by remote ion-pairing in the baseassisted $\mathrm{C}-\mathrm{H}$ bond activation step.

A very original case for simultaneous pre-organization of both substrates and catalysts was shown by the Reek group thanks to multiple ion pairing inside coordination-driven spheres. ${ }^{74}$ Up to 24 cationic guanidinium binding sites were endohedrically oriented and served as a platform to interact with both anionic sulfonate-containing gold catalysts and carboxylate-containing substrates (Scheme 10). The binding was two orders of magnitude higher for sulfonates than for carboxylates inside these spheres. As a result, the gold catalysts were well fixed whereas the carboxylate substrates were more dynamic enabling their entrance and release, which is important for successful turnovers in catalysis. An on/off catalyst switch was showcased by using a more competitive sulfonate binder as well as a preliminary application to substrate-selective catalysis. This strategy also enabled to increase the gold concentration in the spheres at $>1 \mathrm{M}$, which was used to study the effect of local gold concentrations in several gold-catalyzed cycloisomerization reactions. ${ }^{75}$ The same type of guanidinium-containing spheres were used to encapsulate up to 12 sulfonate-containing copper catalysts via ion pairing. ${ }^{76}$ This supramolecular design favoured an unexpected dinuclear catalytic pathway that translated into reactions with increased rates and turnover numbers compared to the reactions in the bulk. 


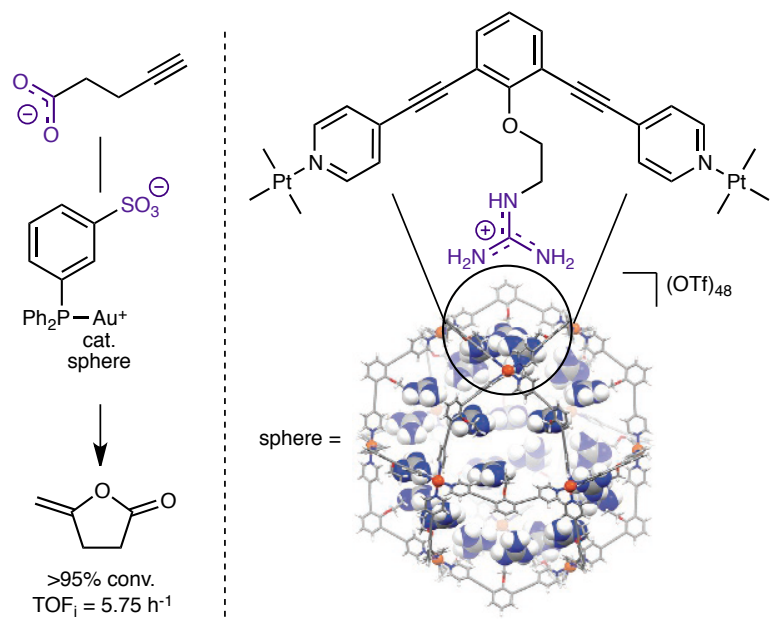

Scheme 10. Coordination-driven spheres self-assemble both sulfonated gold catalysts and anionic substrates providing enhanced reactivities when compared to the bulk catalyst in solution. Adapted with permission from Springer Nature Limited.

\section{Cation “.'crown ether interactions.}

\subsection{Cation "'crown ether interactions as cofactors or regulating} agents.

One of the major breakthroughs of supramolecular chemistry was the discovery by Nobel-laureate Pedersen of crown ethers ability to bind to alkali metal cations via multiple electrostatic interactions between the cation and the crown ether oxygen lone pairs. ${ }^{77-78}$ The association constants for this type of noncovalent interactions depend on the nature of the crown ether, i.e. the number of oxygen atoms available for binding and the spatial conformation, or the presence of additional heteroatoms. $^{79}$ In this context, the merger of these non- covalent interactions with transition metal catalysis has been in-depth reviewed. ${ }^{\mathbf{8 0}-82}$ Aiming to highlight herein only those recent examples, in which a clear control by the second coordination sphere is evident, the contributions from Fan and Vidal-Ferran, independently, are remarkable (Figure 2). They reported a number of chiral bis-phosphite ligands containing distal oligo(ethyleneglycol) backbones of different lengths and shapes. The overarching concept is that the flexible crown ether chain will fold in the presence of Group 1 alkali metal cations bringing nearby the two donor phosphorus atoms (P) for coordination to a transition metal centre (M). Moreover, the geometry adopted in the remote binding of the alkali cation to the crown ether translates into a different coordination mode within the active site, for instance, providing different P-M-P bite angles that affect the activity and selectivity of the catalysis. In particular, this strategy was successfully illustrated in asymmetric rhodium-catalyzed transformations (hydroformylation, hydrogenation) 83-86 $^{\text {and }}$ asymmetric palladium-catalyzed allylic substitutions. ${ }^{87}$ Related versions for copper and gold catalysis, respectively, have been identified recently. ${ }^{\mathbf{8 8}-89}$ Overall, these alkali cations might be considered as regulating agents analogous to the cofactors that appear in enzymes, as they modify the catalyst reactivity far from the active site (allosteric effect). ${ }^{90}$ A similar supramolecular design based on a chelating diphosphane and a pyridine-containing crown ether has been successfully applied in asymmetric rhodium- and iridium-catalyzed hydrogenations. ${ }^{91}$

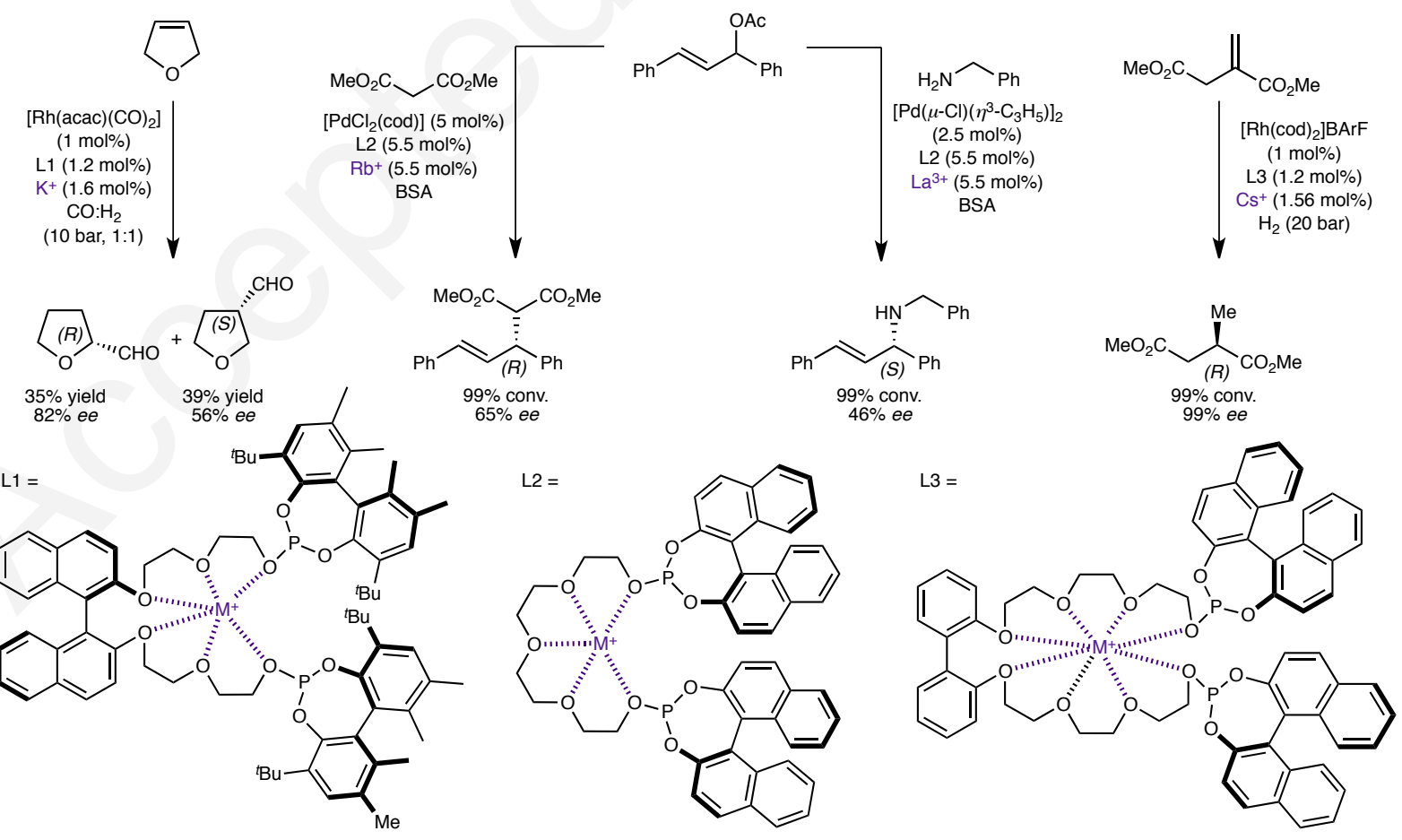


Figure 2. Chiral bisphosphite ligands appended with a crown ether self-fold in the presence of different cations $\left(\mathrm{K}^{+}, \mathrm{Rb}^{+}, \mathrm{La}^{3+}\right.$ or $\left.\mathrm{Cs}^{+}\right)$leading to highly asymmetric transformations under rhodium catalysis (hydroformylation, hydrogenation) or palladium catalysis (allylic alkylation).

This supramolecular strategy was demonstrated viable also for asymmetric Henry reactions between nitromethane and benzaldehydes when using Jacobsen-type chromium(III) salen complexes as catalytically active sites. ${ }^{92}$ As the mechanism is strongly supported to be dinuclear, ${ }^{93}$ the presence of catalytic amounts of $\mathrm{K}^{+}$brings closer the two chromium centres, leading a 13-fold enhance in the reactivity (Scheme 11).

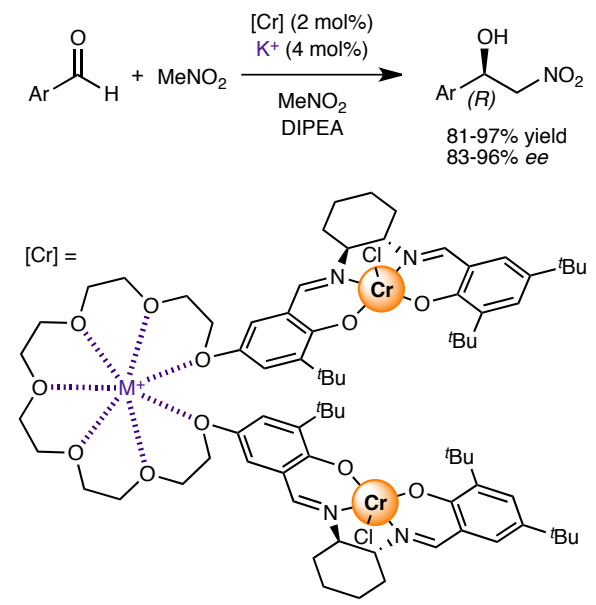

Scheme 11. The chromium-catalyzed asymmetric Henry reaction is feasible due to remote interactions between $\mathrm{K}^{+}$and a crown ether moiety in the dinuclear catalyst.

Interestingly, this type of interactions were used for switching ON/OFF the catalytic activity. The Fan group developed (S)-Aza-CrownPhos supramolecular ligand consisting on a phosphoramidite backbone, which is known to be a suitable ligand for metal-catalyzed asymmetric hydrogenations, appended with crown ether including a nitrogen heteroatom. ${ }^{94}$ They showed that the coordination geometry around the phosphorus bis-ligated rhodium centre was controlled by the presence or absence of sodium cations (Scheme 12). When $\mathrm{Na}^{+}$cations were in the reaction media, they bound the heterocyclic crown ether leaving the rhodium centre available for engaging in asymmetric hydrogenation of dehydroamino acid esters (ON state). On the other hand, in the absence of $\mathrm{Na}^{+}$cations, the phosphorus bis-ligated rhodium centre was simultaneously interacting with both heterocyclic crown ethers, thereby inhibiting its catalytic activity (OFF state). The power of this strategy was further demonstrated by an in situ switch of reactivity following sequential addition of $\mathrm{Na}^{+}$(ON state) and [2.2.2]cryptand as $\mathrm{Na}^{+}$scavenger (OFF state) in a couple of cycles.
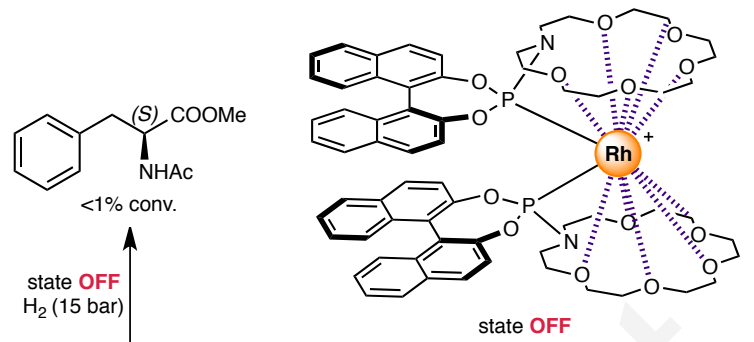<smiles>COC(=O)/C(=C/c1ccccc1)C(C)=O</smiles>

state OFF
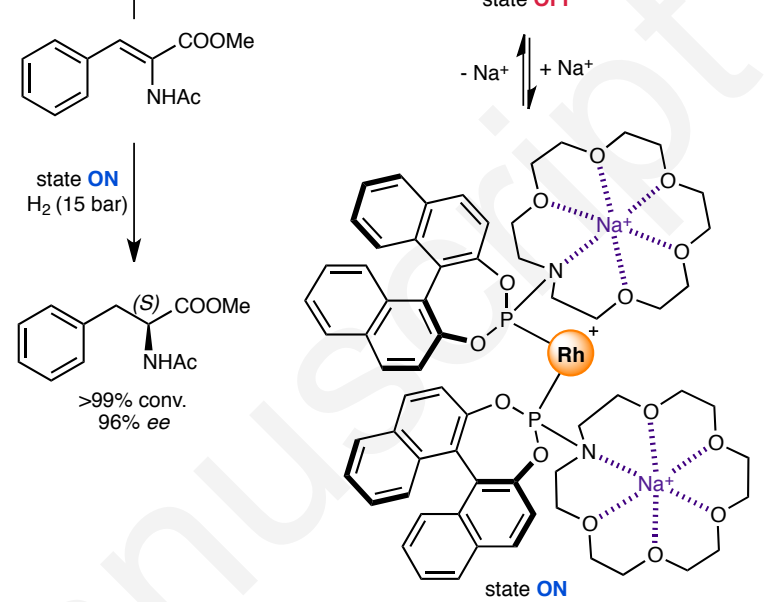

Scheme 12. The addition and removal of $\mathrm{Na}^{+}$alternatively leads to an in situ control of the activity (ON/OFF) of a rhodium catalyst.

\subsection{Cation "'crown ether interactions for substrate pre- organization.}

Following the foundational work in palladium catalysis using crown ether functionalized ligands by Ito and Sawamura for substrate pre-organization, ${ }^{95}$ in 2017, Costas and co-workers built up the first supramolecular metal catalyst exhibiting control in the site-selectivity via substrate pre-organization by means of cation $\cdots$ crown ether interactions. ${ }^{96} \mathrm{~A}$ bispyridinebipyrrolidine-coordinated manganese complex was covalently equipped with two remote crown ether receptors featuring a site-selectivity ( $>50 \%$ ) for the C8 and C9 oxidation of aliphatic ammonium salts, which is outstanding considering that the reactivity of all the aliphatic $\mathrm{C}-\mathrm{H}$ bonds are energetically very similar. This unusual reactivity was a direct consequence of the suitable size and shape complementarity between the ammonium $\cdots$ crown ether recognition site and the catalytically active manganese site (Scheme 13). The transition state for this system may adopt a very large 20-membered cycle, showing that even if the substrate recognition and the catalytically active sites are significantly wide apart, the selective catalysis can take place. Application towards substrate-selectivity employing mixtures of substrates was disclosed. ${ }^{97}$ Related iron and manganese catalysts were employed in the highly predictive oxidation of steroids at the challenging C15 and C16 positions (Scheme 13, framed). ${ }^{\mathbf{9 8}}$ Conventional catalysts will oxidize the most reactive $\mathrm{C} 25$ position or they will rather form statistical mixture of products in other cases, thus these supramolecular catalysts serve to reverse classical selectivities. 

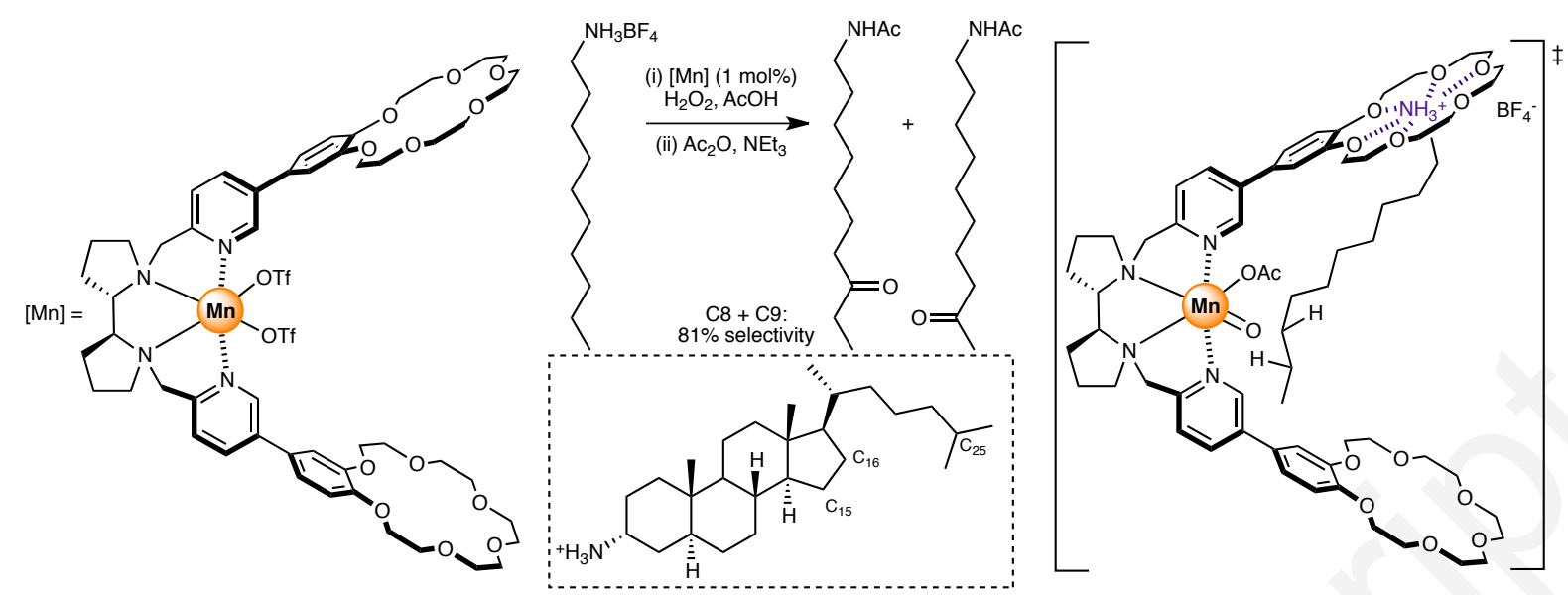

Scheme 13. The substrate-preorganization via ammonium "crown ether interactions within a manganese catalyst is responsible for the remote selectivity observed in the oxidation of alkanes.

\section{4. $\pi$ interactions.}

\section{1. $\mathrm{CH}^{\cdots} \mathrm{\pi}$ interactions.}

Reactions controlled by aromatic $\pi$ interactions have witnessed a tremendous impact in organic synthesis and in asymmetric organocatalysis in particular. ${ }^{99}$ The rational influence of such subtle interactions (typically $<3 \mathrm{kcal} / \mathrm{mol}$ for the simplest case) in homogeneous, transition metal catalysis is still underexploited and it is usually detected a posteriori. This was the case for the seminal contribution from Noyori unraveling the unexpected role of $\mathrm{CH} \cdots \pi$ interactions for stabilizing the enantio-determining transition state in the ruthenium-catalyzed transfer hydrogenation of aromatic ketones that boosted further research in similar directions. ${ }^{100}$ Examples of metal-catalyzed reactions controlled by noncovalent $\pi$ interactions in the first coordination sphere are known, ${ }^{101-105}$ but they are beyond the scope of this review. In 2018, the group of Mezzetti described a thorough computer- guided, rational design of P-stereogenic iron pincer catalysts for the asymmetric hydrogenation of acetophenone taking benefit from $\mathrm{CH} \cdots \pi$ interactions occurring in the second coordination sphere. ${ }^{106} \mathrm{~A}$ modest enantiomeric excess was observed for one of the iron catalysts which was rationalized by the presence of a single of these non-covalent interactions between a $\mathrm{CH}$ bond from the ligand and the aromatic ring from the substrate compatible with the well-accepted Noyori's bifunctional mechanism (Scheme 14, left). Similar findings were identified replacing $\mathrm{Fe}(\mathrm{II})$ by $\mathrm{Mn}(\mathrm{I})$, although the system was less active. ${ }^{107}$ In a very recent contribution, the same group developed an elegant $\mathrm{Mn}(\mathrm{I})$ catalyst derived from a $(\mathrm{NH})_{2} \mathrm{P}_{2}$ macrocyclic ligand (Scheme 14, right) to access the $R$ enantiomer with excellent enantioselectivity ( $>99 \%$ ee) and a broad functional group tolerance. ${ }^{108}$ This time, multiple $\mathrm{CH} \cdots \pi$ non-covalent interactions between the substrate and the ligand were at play (Scheme 14, right).

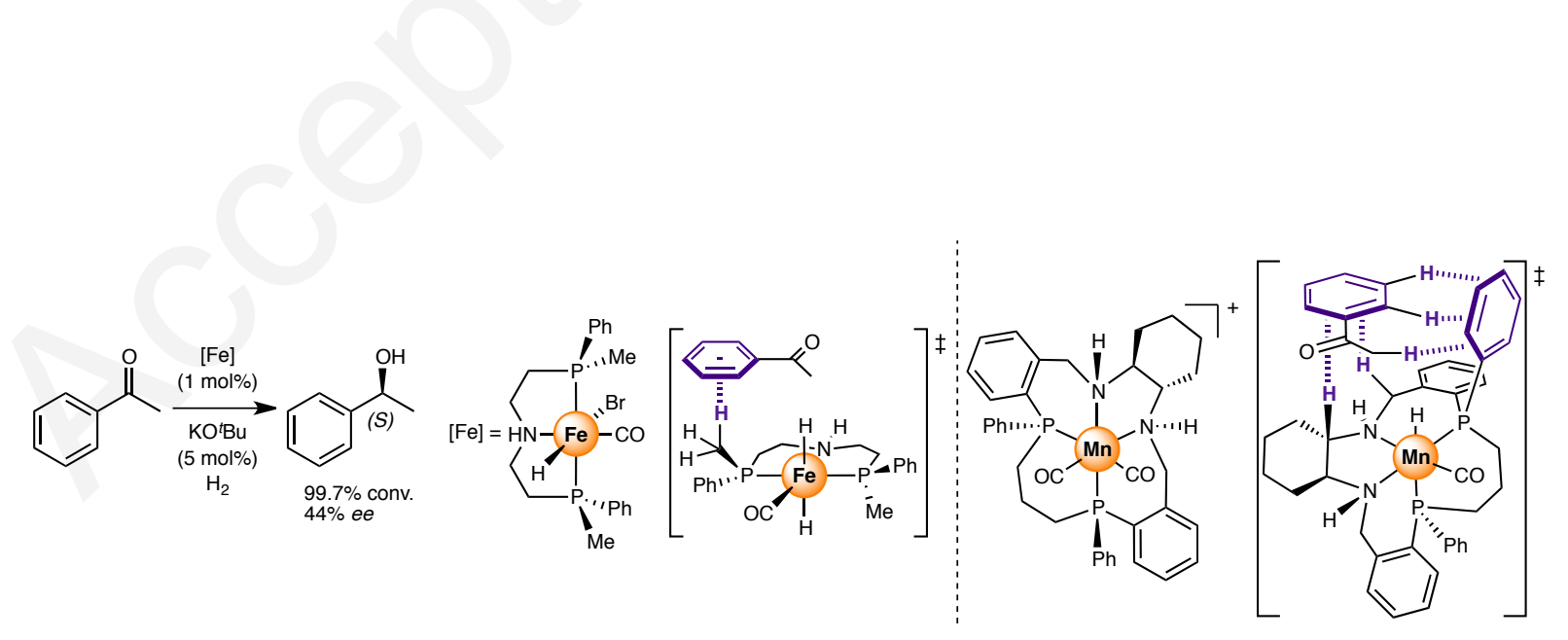

Scheme 14. The $\mathrm{CH} \cdots \pi$ interactions stabilize transition states in iron- and manganese-catalyzed asymmetric hydrogenation. 
Analogously, Korenaga and co-workers reported a rhodium-catalyzed asymmetric 1,4-addition of arylboronic acids to coumarin in which a fluorinated MeO-BIPHEP ligand was computationally identified on the basis of exclusive $\mathrm{CH} \cdots \pi$ interactions between the ligand and the coumarin substrate (Scheme 15). ${ }^{109}$

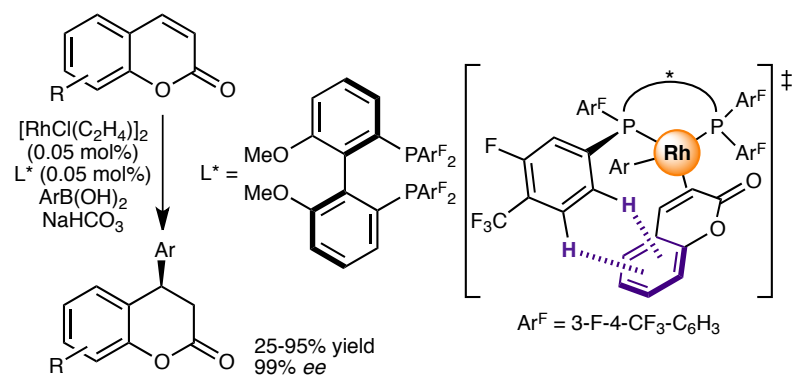

Scheme 15. A rhodium-catalyzed asymmetric 1,4-addition was controlled by remote $\mathrm{CH} \cdots \pi$ interactions.

Although $\mathrm{CH} \cdots \pi$ interactions are rather weak non-covalent interactions, they turned out to be significantly relevant when associated with other non-covalent interactions, typically, hydrogen bonding. For instance, this was demonstrated by Sigman and co-workers in the palladium-catalyzed enantioselective 1,1-diarylation of benzyl acrylates (Scheme 16), ${ }^{110}$ and by Toste, Sunoj and co-workers in the palladiumcatalyzed enantioselective Heck-Matsuda arylation of a spyrocyclic pentene (Scheme 17). ${ }^{\mathbf{1 1 1}}$ Sunoj and co-workers also identified similar features a posteriori in the asymmetric amination of alcohols by means of in situ dual catalysis utilizing a phosphoric acid organocatalysts and a $\mathrm{Cp}^{*} \operatorname{Ir}$ (diamine) as the transition metal catalyst. ${ }^{\mathbf{1 1 2}}$ Similarly, Baudoin, Clot and coworkers found that $\mathrm{CH} \cdots \pi$ interactions played a key role in intramolecular, asymmetric Pd-catalyzed functionalization of $\mathrm{C}\left(\mathrm{sp}^{3}\right)$-H bonds. ${ }^{113}$

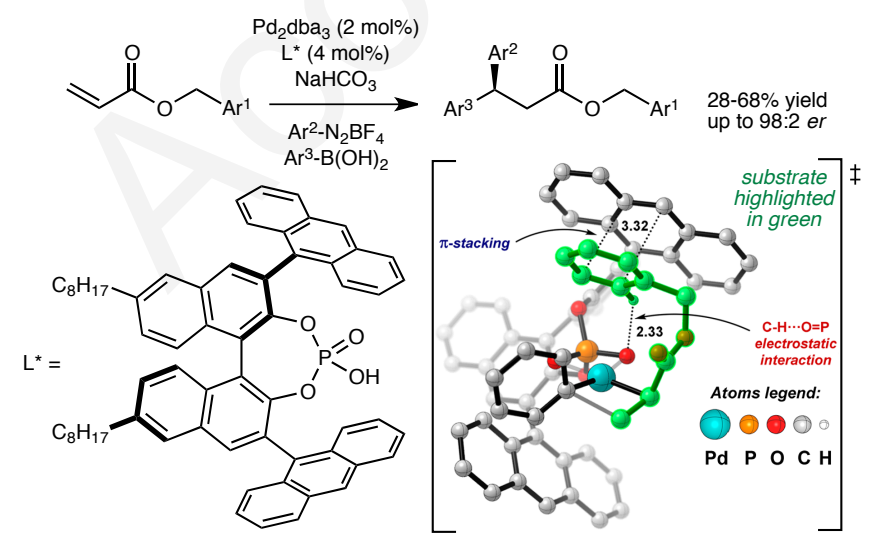

Scheme 16. The palladium-catalyzed enantioselective 1,1-diarylation of benzyl acrylates is assisted by a combination of remote $\mathrm{CH} \cdots \pi$ interactions and hydrogen bonding. Adapted with permission from the American Chemical Society.

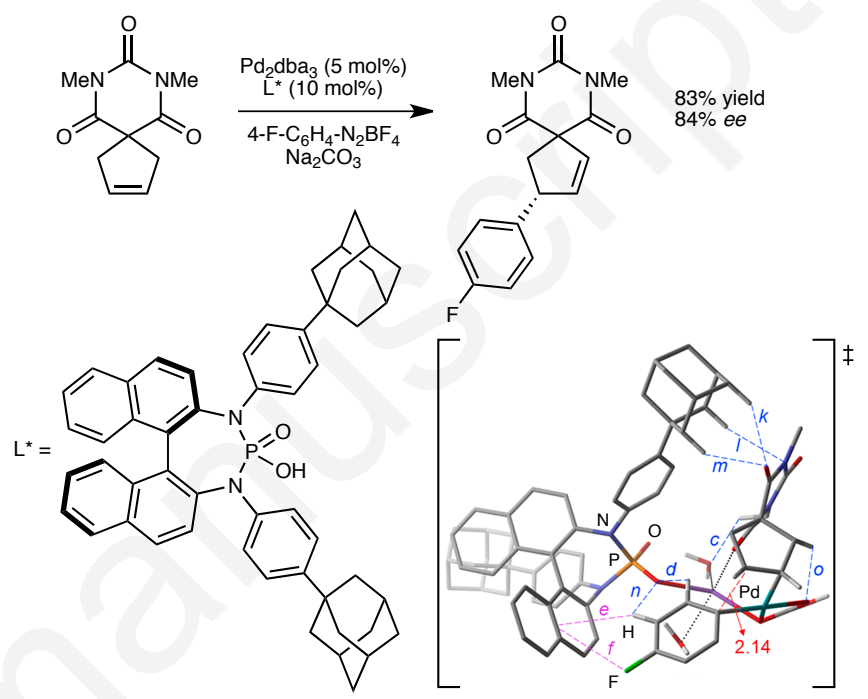

Scheme 17. Multiple weak interactions, some involving $\mathrm{CH} \cdots \pi$ interactions, lead to highly asymmetric palladium-catalyzed HeckMatsuda arylation. Adapted with permission from the American Chemical Society.

\section{2. $\pi . . . \pi$ interactions.}

Regarding transition metal catalysis exclusively directed by secondary $\pi \cdots \pi$ interactions, the group of Schomaker and Berry reported an interesting silver-catalyzed nitrene transfer highlighting such feature. ${ }^{114}$ The highly regio- and diasteroselective intramolecular $\mathrm{C}-\mathrm{H}$ bond amination was largely driven by $\pi \cdots \pi$ stacking between the aromatic benzylic group from the substrate and one of the pyridine rings attached to the catalytically relevant, cationic silver centre (Scheme 18). Such level of understanding enabled the successful utilization of this catalyst with challenging substrates to discriminate between energetically comparable $\mathrm{C}-\mathrm{H}$ bonds. 


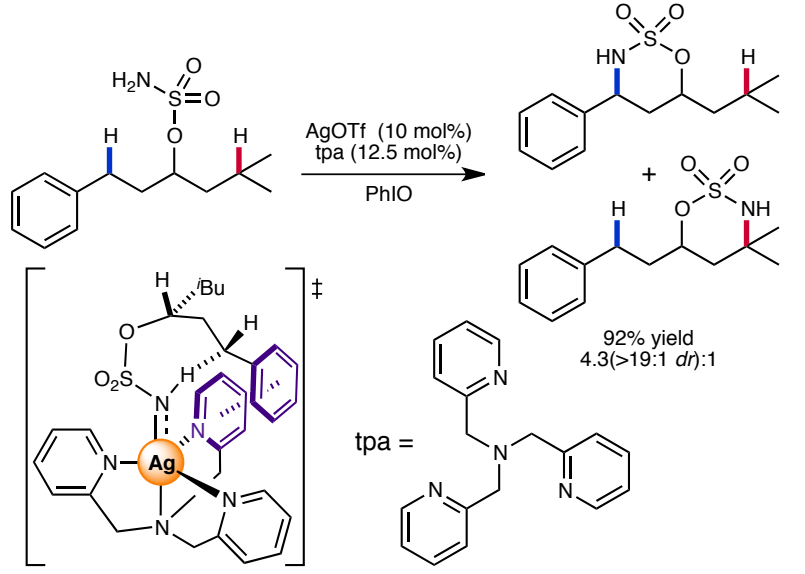

Scheme 18. The site- and diastereo-selectivity in silver-catalyzed $\mathrm{C}-\mathrm{H}$ bond aminations is guided by remote $\pi \cdots \pi$ interactions.

In a subsequent study, a similar strategy was implemented by Chang and co-workers in a site-selective rutheniumcatalyzed $\mathrm{C}-\mathrm{H}$ bond functionalization. ${ }^{115}$ A mechanism-assisted design allowed the identification of a ruthenium-coordinated phenanthroline derivative as an unprecedented ligand for the selective intramolecular $\mathrm{C}-\mathrm{H}$ bond amidation in the benzylic position over a tertiary one in the same substrate (Scheme 19). The relevance of remote $\pi \cdots \pi$ stacking in the second coordination sphere of the catalyst between the substrate and the ligand was evidenced by in-depth mechanistic studies and theoretical calculations. Very recently, Sawamura and coworkers reported a remote $\mathrm{C}\left(\mathrm{sp}^{3}\right)-\mathrm{H}$ borylation at the $\mathrm{\gamma}$ position of aliphatic amides and esters. ${ }^{116}$ In the presence of a chiral phosphite and a urea-functionalized ligand, the iridiumcatalyzed $\mathrm{C}-\mathrm{H}$ borylation circumvented the classical reactivity patterns at $\alpha$ and $\beta$ position due to a combination of secondary $\pi \cdots \pi$ interactions and hydrogen bonding (Scheme 20). A previous design comprised $\pi \cdots \pi$ interactions between the ligand and a pyridine-containing substrate also for asymmetric iridium-catalyzed borylation. ${ }^{117}$

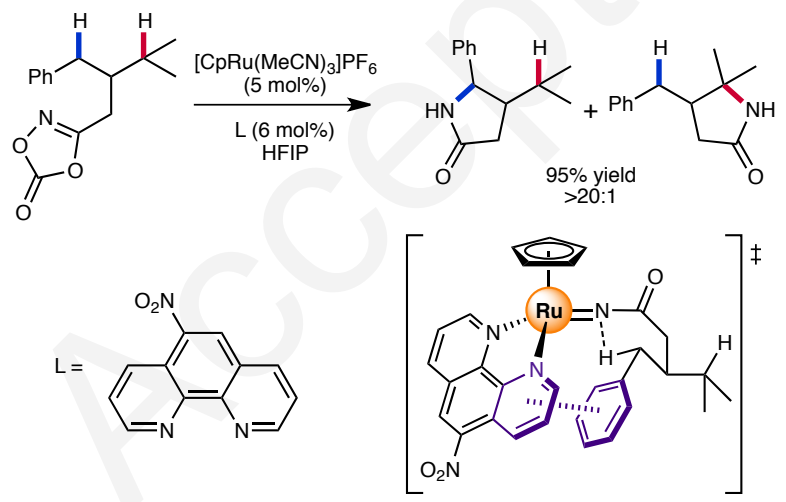

Scheme 19. The $\pi \cdots \pi$ interactions between the aromatic fragments in the ligand and the substrate dictate the site-selectivity in rutheniumcatalyzed $\mathrm{C}-\mathrm{H}$ bond amidations.

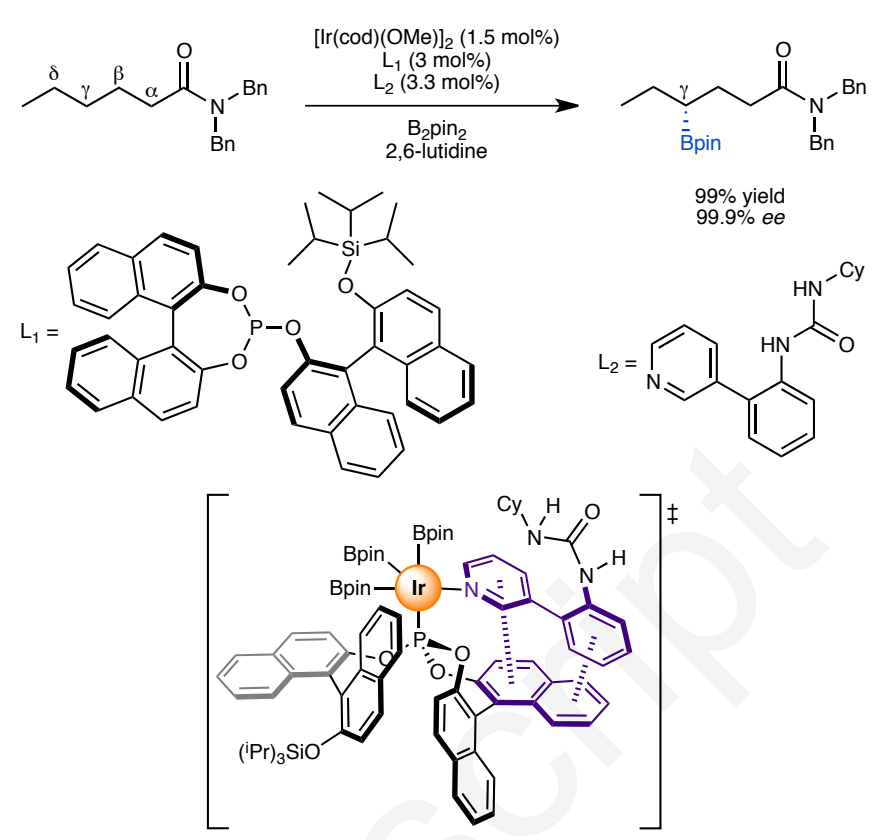

Scheme 20. Remote enantio-selectivity in the iridium-catalyzed $\mathrm{C}-\mathrm{H}$ bond borylation with a ligand self-assembling by $\pi \cdots \pi$ interactions.

\subsection{Cation... $\pi$ interactions.}

In the last decades, cation $\cdots \pi$ interactions have been studied by many research groups interested in organocatalysis, fine chemistry and organometallics. ${ }^{\mathbf{1 1 8 - 1 2 0}}$ Unfortunately, little is known to benefit from this type of interaction in transition metal homogeneous catalysis. The group of Walsh reported an appealing palladium-catalyzed benzylic arylation of toluene derivatives controlled by remote $\mathrm{K}^{+} \cdots \pi$ non-covalent interactions. $^{121}$ The palladium-coordinated NIXANTPHOS ligand was responsible for this unique action mode thanks to the remote binding of nitrogen to potassium in such a way that the aromatic toluene ring binds to the latter (Scheme 21). This translates into a unique transition state including a network of multiple interactions to access the key benzylic $\mathrm{C}-\mathrm{H}$ bond activation/deprotonation step prior to the cross-coupling palladium events with the aryl bromide coupling partner. An expansion of this methodology towards aryl chlorides was shown by the same group using nickel catalysis and $\mathrm{Na}^{+}$for the remote cation $\cdots \pi$ interaction. ${ }^{\mathbf{1 2 2}}$

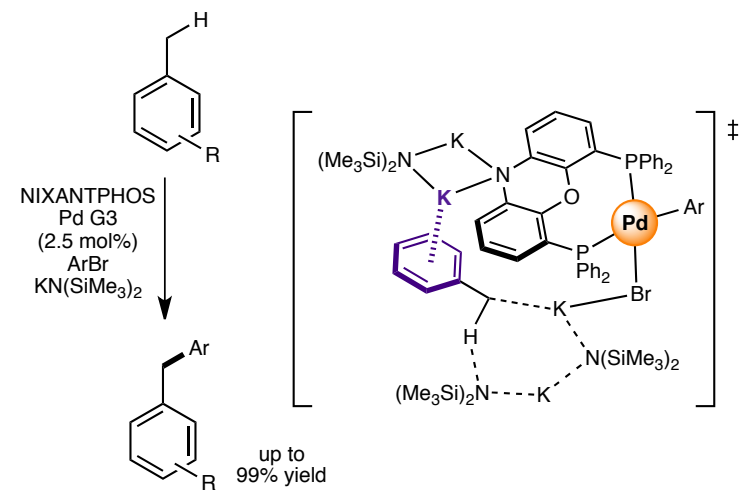

Scheme 21. The palladium-catalyzed benzylic arylation was possible due to remote $\mathrm{K}^{+} \cdots \pi$ interactions. 
Analogously, a posteriori computational studies have revealed that $\mathrm{Cs}^{+} \cdots \pi$ non-covalent interactions were involved in key intermediates for several palladium-catalyzed $\mathrm{C}-\mathrm{H}$ bond functionalizations ${ }^{\text {123-126 }}$ and nickel-catalyzed C-O bond functionalizations, ${ }^{127}$ although it remains difficult to categorize them as secondary interactions. The Miller group also postulated that distal $\mathrm{Cs}^{+} \cdots \pi$ non-covalent interactions may explain the high enantioselectivity observed in some coppercatalyzed reactions using peptide-based ligands (Scheme 22). ${ }^{128-129}$ A more complex threefold cation $\cdots \pi \cdots \pi$ interaction was evoked in a silver-catalyzed cycloisomerization. ${ }^{130}$

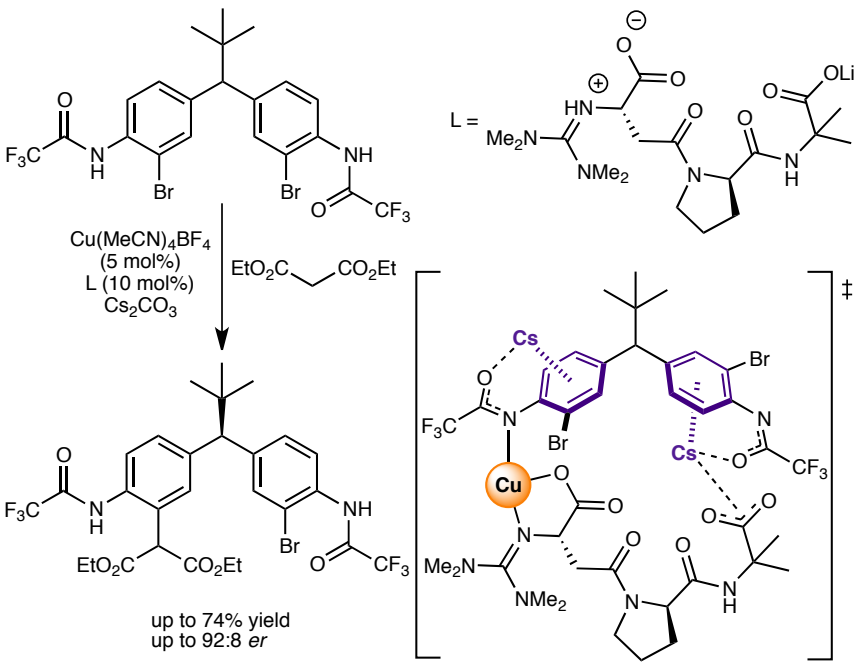

Scheme 22. The copper-catalyzed enantioselective desymmetrization of diarylmethane-based aryl bromides via secondary $\mathrm{Cs}^{+} \ldots \pi$ interactions.

\section{Halogen bonding.}

In the last decade, organic transformations mediated by halogen bonding have received increasing attention. ${ }^{\mathbf{1 3 1 - 1 3 2}}$ However, their use in transition metal catalysis remains extremely rare to date since the pioneering discoveries from Charette's group in 2009 demonstrating that chiral, Davies' rhodium cyclopropanation catalysts undergo an intramolecular halogen bonding network responsible for the all-up conformation that accounts for the excellent enantioselectivity observed employing this type of catalysts. ${ }^{133-134}$ It was not until 2018 that Vidal-Ferran and co-workers reported the first example of a rationally-designed supramolecular rhodium catalyst taking benefit from a unidirectional intermolecular halogen bonding. ${ }^{135-136}$ lodo-containing phosphanes and 2pyridylphosphane self-assemble in the presence of a rhodium complex leading to heteroleptic rhodium-carbonyl complexes featuring $\mathrm{N} \cdots \mathrm{I}$ halogen bonding. The iodine atom was additionally involved in coordination to the square-planar $\mathrm{Rh}(\mathrm{I})$ atom. These cationic rhodium complexes were remarkably stable in solution and in the solid state. Application to hydroboration of alkynes demonstrated that these systems are similarly reactive as $\left[\mathrm{Rh}(\mathrm{CO})\left(\mathrm{PPh}_{3}\right)_{3}\right]^{+}$, although a different regio-selectivity (linear/branched) was observed (Scheme 23).

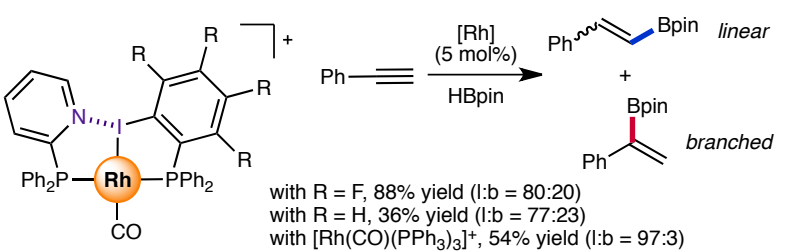

Scheme 23. The $\mathrm{N} \cdots \mathrm{I}$ halogen bonding is used to self-assemble a rhodium catalyst that leads to high activity and branched-selectivity in the hydroboration of alkynes.

Halogen bonding can be rationally utilized for fixing a substrate in a precise conformation as Chevalier and coworkers showed. They reported a highly selective rutheniumcatalyzed 1:1 macrocyclization enabled by a halogen-bonded template comprising a tetra(iodoperfluorophenyl) ether scaffold. ${ }^{137}$ The template was previously developed by Metrangolo and Resnati and was known for giving rise to a highly pre-organized conformation because of $\pi \cdots \pi$ stacking as well. ${ }^{138}$ In the catalytic system, the tetra(iodoperfluorophenyl) ether scaffold was bound to the bisallyl-functionalized $\mathrm{N}$ heterocycle substrate via $\mathrm{N} \cdots \mathrm{I}$ halogen bonding in a 1:2 stoichiometry, thereby locating the terminal alkene fragments at close enough proximity for the ruthenium catalyst to perform selectively the 1:1 olefin metathesis reaction followed by in situ hydrogenation with $\mathrm{NaBH}_{4}$ (Scheme 24). Interestingly, the reaction required only catalytic amounts of template and the catalytic outcome was correlated with the strength of the $\mathrm{N} \cdots \mathrm{X}$ halogen bonding utilizing other tetra(haloperfluorophenyl) ether scaffolds. Excellent isolated yields in the range of $90 \%$ were obtained for this challenging dimerization, which under classical reaction conditions should have formed substantial amounts of oligomeric side-products.

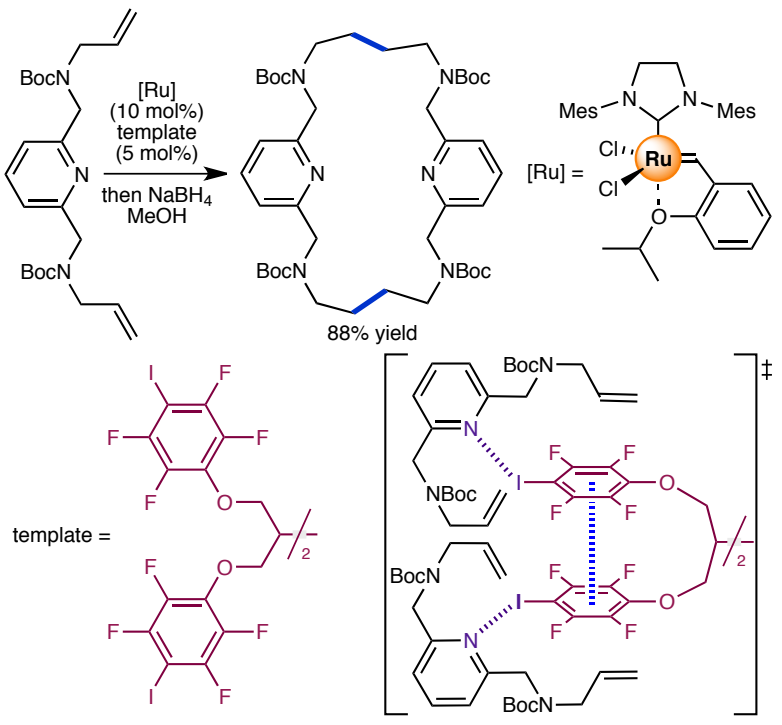

Scheme 24. A tetra(iodoperfluorophenyl) ether template preorganizes two substrates via $\mathrm{N} \cdots \mathrm{l}$ halogen bonding prior to the ruthenium-catalyzed olefin metathesis macrocyclization.

The groups of Arai and Yamanaka demonstrated the relevance of halogen bonding for the zinc-catalyzed asymmetric iodolactonization. ${ }^{139}$ By means of control 
experiments and thorough theoretical calculations, a key halogen bonding between $I_{2}$ and both reagents, the carboxylate-containing alkene substrate and $\mathrm{N}$ iodosuccinimide (NIS), was proved (Scheme 25). This revealed that the true iodinating agent was $I_{2}$ and not the expected NIS with a catalytic cycle that regenerates $I_{2}$ every turnover. As such, catalytic amounts of $I_{2}$ were enough to reach high levels of activity and asymmetric induction for this zinc-catalyzed transformation. Importantly, the key transition state of the reaction was accessible with a decrease of $>10 \mathrm{kcal} / \mathrm{mol}$ owing to the secondary halogen bonding. Very recently, Kitamura and co-workers reported a highly enantioselective rutheniumcatalyzed intramolecular cyclization of $\mathrm{N}$-tethered pyrroles facilitated by secondary halogen bonding between a chloride substituent from the ligand and the aromatic cloud of the pyrrole unit (Scheme 26). ${ }^{140}$

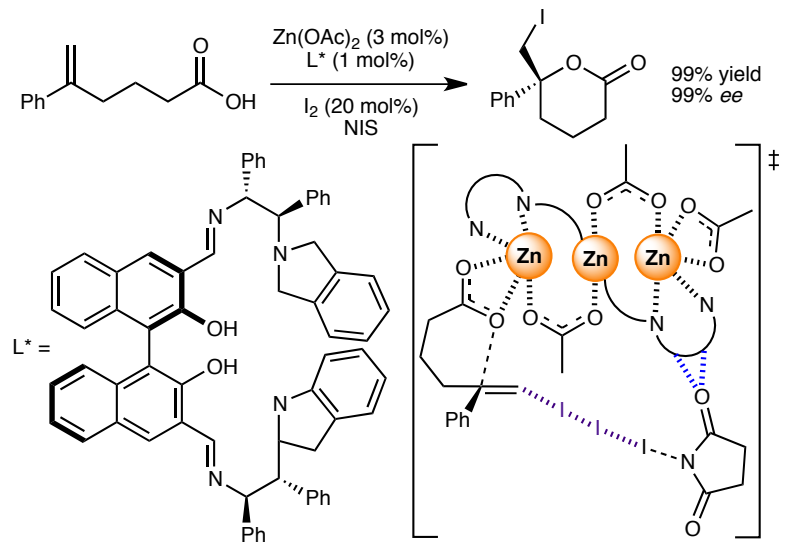

Scheme 25. The zinc-catalyzed asymmetric iodolactonization is dictated via a unique $|\cdots| \cdots \mid \cdots \mathrm{N}$ halogen bonding network (blue dashed lines indicate hydrogen bonding).

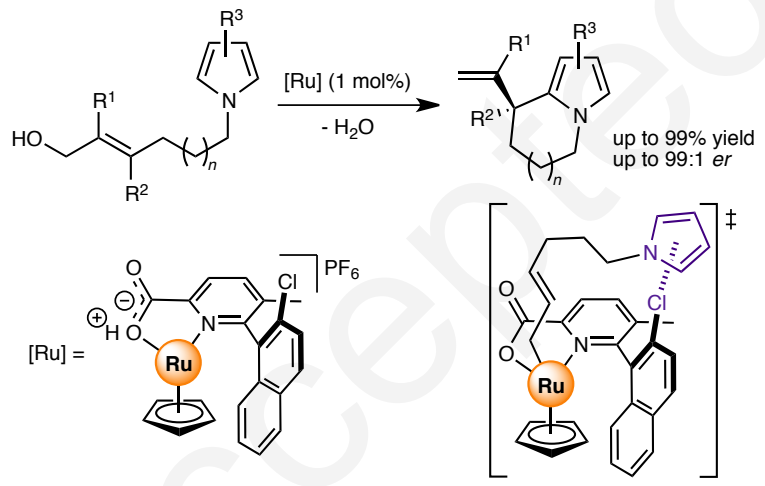

Scheme 26. The ruthenium-catalyzed allylative cyclization of pyrroles tethered at $\mathrm{N}(1)$ with allylic alcohols exploiting secondary halogen bonding.

\section{Lewis adducts.}

\subsection{Lewis adducts for substrate pre-organization.}

In contrast to the previously described array of non-covalent interactions, the next ones cannot be categorized as noncovalent but dative, however, they share the reversible nature of the interaction, which makes them suitable for reaching turnovers in catalysis. For instance, organocatalysis exploiting Lewis acid $\cdots$ base adducts formation is well recognized in organic synthesis, ${ }^{141}$ however their rational use in transition metal catalysis is poorly developed. ${ }^{\mathbf{1 4 2}}$ Thereby, their successful application in transition metal catalysis is exemplified by the major breakthroughs reported by the groups of Kanai and Nakao, respectively. They designed different bipyridine derivative ligands appended with a remote Lewis acid site enabling transient interaction with substrates comprising Lewis base functionalities. ${ }^{143-144}$ After substantial ligand optimization, well-defined boron-containing acidic sites turned out to be suitable for interacting with sulfide fragments from thioanisole substrates and nitrogen atoms from 2substituted pyridine substrates, respectively. When applied in iridium-catalyzed aromatic $\mathrm{C}-\mathrm{H}$ bond borylations, orthoborylated thioanisoles (Scheme 27, top) and meta-borylated 2substituted pyridines (Scheme 27, bottom) selectively formed due to the ideal pre-organization of the substrate around the catalyst to reach this regioselectivity. That corresponds to the completely reversed regioselectivity that is obtained with a system lacking the remote Lewis acid functionality.

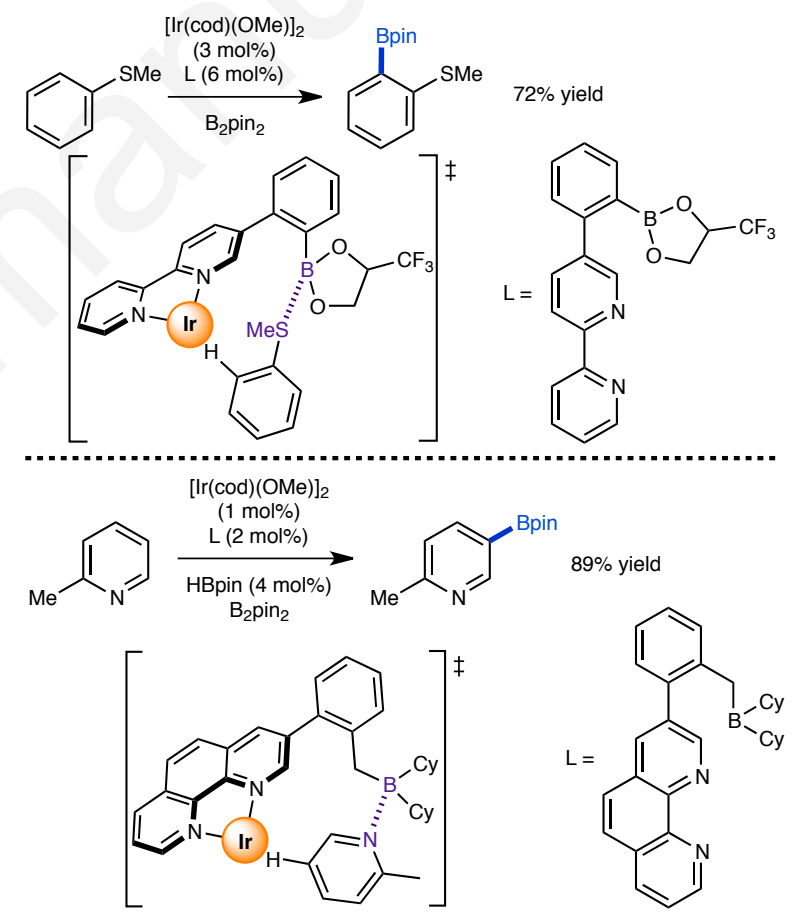

Scheme 27. Bipyridine ligands appended with boron sites control the regioselectivity of iridium-catalyzed aromatic $\mathrm{C}-\mathrm{H}$ bond borylations via secondary $\mathrm{B} \cdots \mathrm{S}$ and $\mathrm{B} \cdots \mathrm{N}$ interactions

In the same vein, Nakao and co-workers also showed the aptitude of aluminium-containing fragments to act as Lewis acidic sites for this type of catalysis. ${ }^{144}$ In particular, benzamide derivatives gave rise to meta-selective borylated products due to the unique interaction between the carbonyl from the amide group and the aluminium centre within the highly preorganized ligand-to-substrate key intermediate (Scheme 28). 

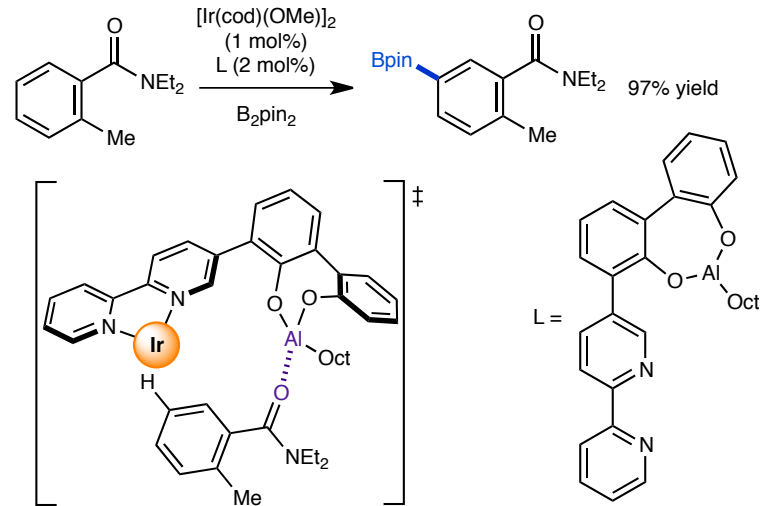

Scheme 28. A bipyridine ligand substituted with an aluminium site guides the meta-selectivity of iridium-catalyzed aromatic $\mathrm{C}-\mathrm{H}$ bond borylations via secondary $\mathrm{Al} \cdots \mathrm{O}=\mathrm{C}$ interactions.

\subsection{Lewis adducts beyond ligand design.}

Interestingly, in some cases, the Lewis acid functionality does not need to be covalently attached to the ligand, but just present in catalytic amounts in the reaction mixture. In this way, the Nakao group showed that benzamide and pyridine derivatives, respectively, were able to reversibly interact with aluminium-based Lewis acids (i.e. methylaluminium bis(2,6-ditert-butyl-4-methylphenoxide = MAD), leaving the remote para-C-H bond exclusively available for borylation with an iridium catalyst. ${ }^{145}$ In this case, the formation of the Lewis adduct between the acid and the substrate sterically protects the $\mathrm{C}-\mathrm{H}$ bonds in ortho and meta position (Scheme 29).
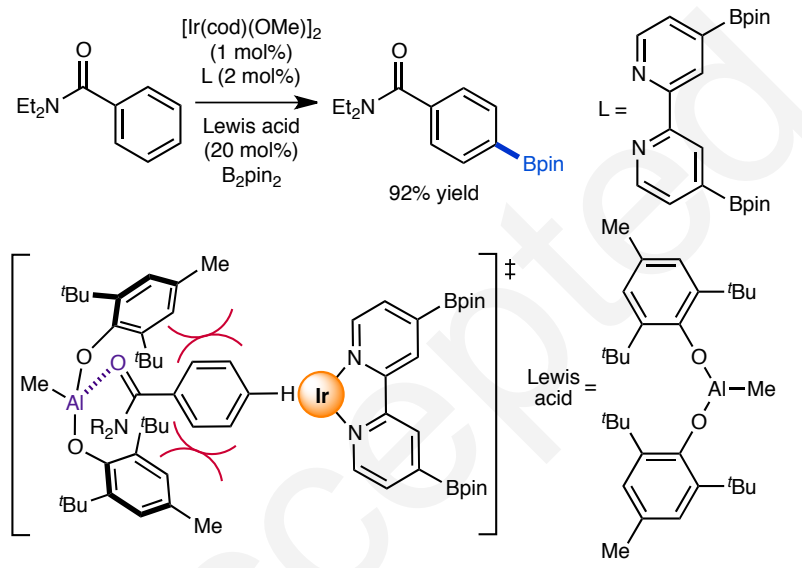

Scheme 29. The para-selectivity of the iridium-catalyzed $\mathrm{C}-\mathrm{H}$ bond borylation of aromatic esters is reached thanks to secondary $\mathrm{Al} \cdots \mathrm{O}=\mathrm{C}$ interactions.

A complementary approach revealed $a$ posteriori by the group of Chattopadhyay relied on $\mathrm{B} \cdots \mathrm{N}$ secondary interactions. ${ }^{146}$ Benzaldehyde derivatives in situ formed the corresponding imines with over-stoichiometric amounts of primary amines that were further engaged in iridium-catalyzed $\mathrm{C}-\mathrm{H}$ bond borylation using 3,4,7,8-tetramethyl-1,10phenanthroline (TMP) as the ligand (Scheme 30). Control experiments suggested that the meta-selectivity observed in the products was originating from secondary interactions between the Lewis base nitrogen atom from the substrate and the Lewis acid boron centre belonging to an equatorial iridiumligated pinacolato boron moiety. A similar reaction design was conceived through remote $\mathrm{B} \cdots \mathrm{S}$ interactions with aromatic substrates bearing a $\mathrm{X}-\mathrm{CH} 2-\mathrm{SMe}(\mathrm{X}=\mathrm{O}$ or NAc) pendant fragment. ${ }^{147}$ This methodology allowed access to ortho-C-H borylated phenol and anilines after deprotection of the sulfidecontaining moiety.

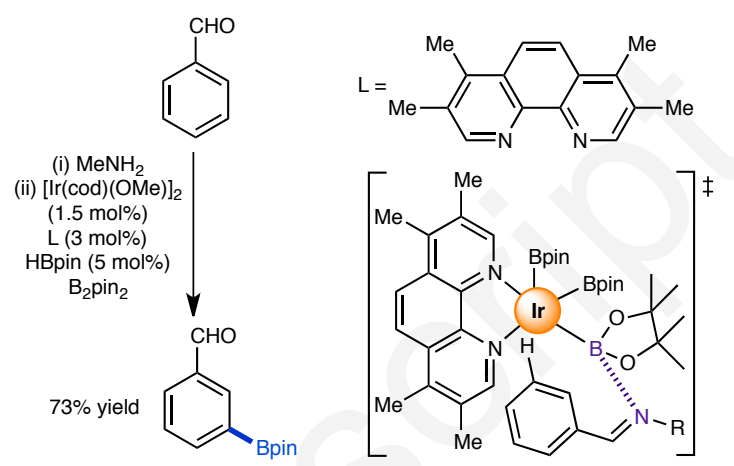

Scheme 30. The secondary $\mathrm{B} \cdots \mathrm{N}$ interactions are exploited for the iridium-catalyzed meta-C-H bond borylation of aromatic imines.

\section{7. $M \cdots N$ coordination.}

\section{1. $\mathrm{Zn} \cdots \mathrm{N}$ coordination for catalyst assembly.}

$\mathrm{Zn} \cdots \mathrm{N}$ coordination between zinc(II)-porphyrins and nitrogen scaffolds have been largely utilized in supramolecular chemistry, material sciences and physical processes (i.e. charge transfer). ${ }^{\mathbf{1 4 8 - 1 4 9}}$ Interestingly, in 2001, the Reek group showed that this type of interaction can be exploited for encapsulating a rhodium catalyst within a trispyridylphosphine via $\mathrm{Zn} \cdots \mathrm{N}$ coordination leading to branched selectivity and high turnover frequencies (up to 400) in the hydroformylation of terminal olefins. ${ }^{150}$ Since then, this type of secondary interactions have been utilized for the construction of effective metal catalysts, which have been reviewed. ${ }^{151}$ Typically, the association constants for the binding between nitrogen scaffolds and $\mathrm{Zn}$ porphyrinoids (or related zinc derivatives) lie in the range $10^{3}$ $10^{5} \mathrm{M}^{-1}$ depending on stereoelectronics. In order to provide a recent overview here, it is worthy to mention the design of new zinc scaffolds to tune the second coordination sphere around the rhodium active site and its implication in hydroformylation catalysis. For instance, zinc-porpholactones bind to the nitrogen atoms of tris(meta-pyridyl)phosphine one order of magnitude higher than their corresponding tetraphenylporphyrin version. ${ }^{152}$ This resulted in an increase of catalyst stability (even in the presence of polar and coordinating solvents) and higher branched-selectivity for the industrially relevant rhodium-catalyzed hydroformylation of propene (Scheme 31). Zinc-porphyrins bearing peripheral Cchiral moieties were used to create a secondary chiral environment around the active rhodium centre, however the level of enantioinduction in the obtained chiral aldehydes was modest (up to $33 \%$ ee). ${ }^{\mathbf{1 5 3}}$ The same tris(metapyridyl)phosphine ligand was able to interact with three Nolte's zinc-porphyrin clips only in the presence of 
methylviologen derivatives as co-factors (Scheme 32). ${ }^{154}$ The formers led to a charge-transfer complex within the clip leaving the zinc centre available for a strong exo-coordination to the nitrogen atoms of the phosphine ligand. ${ }^{155}$ In the presence of rhodium, a confined active catalyst is formed, which displays high activity and selectivity for branched aldehydes in the hydroformylation of terminal olefins. In other words, the active catalyst forms only in the presence of the cofactor, which is rather novel for abiological catalysis.
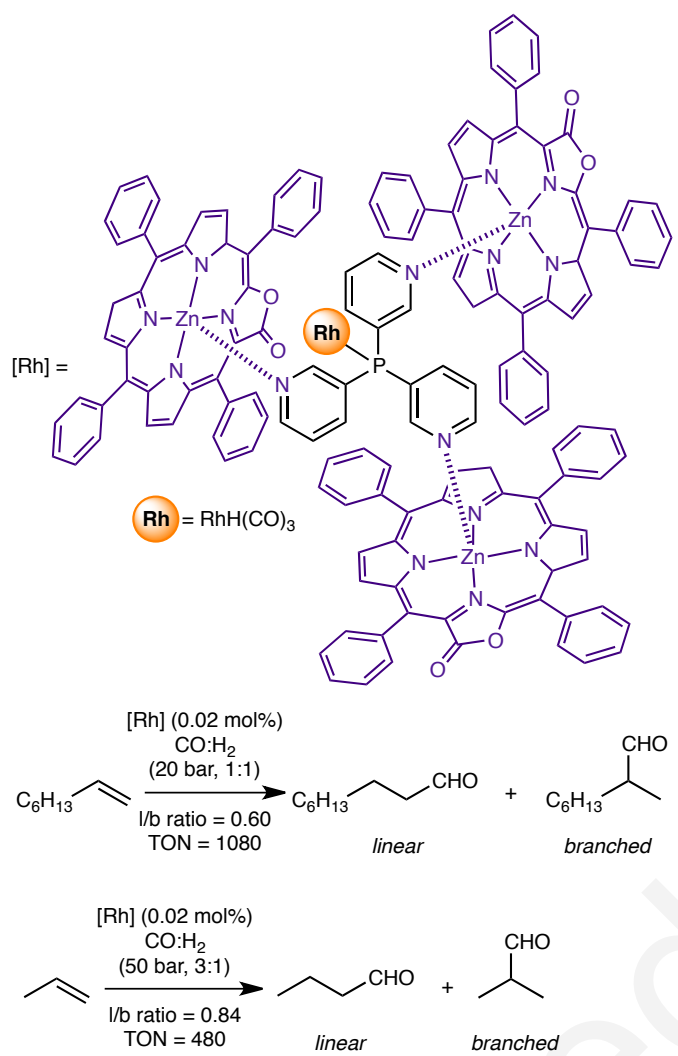

Scheme 31. The tris(meta-pyridyl)phosphine-ligated rhodium catalyst displays high branched selectivity and activity in the hydroformylation of olefins upon peripheral binding to zinc(II) porpholactone via $\mathrm{Zn} \cdots \mathrm{N}$ interactions.

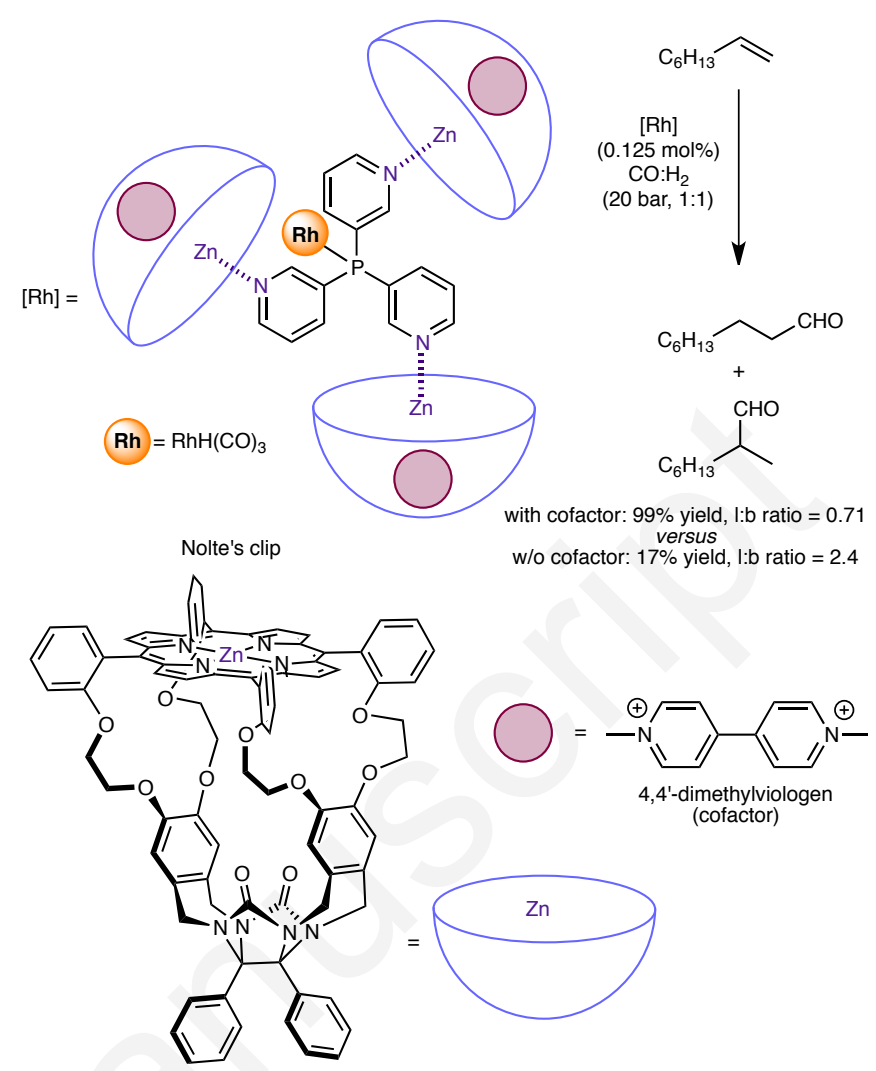

Scheme 32. The association of a cofactor (4,4'-dimethylviologen) within Nolte's zinc(II) porphyrin clip enables remote $\mathrm{Zn} \cdots \mathrm{N}$ interactions with the tris(meta-pyridyl)phosphine-ligated rhodium catalyst leading to high activity and selectivity in the hydroformylation of olefins.

Tris(meta-pyridyl)phosphine ligand was also identified as a suitable ditopic ligand to bind to a [FeFe] hdyrogenase mimic leaving the nitrogen atoms available for interacting with a tetrahedral cage comprising zinc-porphyrin derivatives via $\mathrm{Zn} \cdots \mathrm{N}$ coordination (Scheme 33). ${ }^{\mathbf{1 5 6}}$ The system was applied in the electrocatalytic proton reduction $\left(\mathrm{H}_{2}\right.$ evolution reaction), which is the half reaction of water splitting and it is a relevant catalytic process for green clean energies. Besides high stability, this system significantly decreased the overpotential of the catalysis by $150 \mathrm{mV}$ when compared to the nonconfined one, which is an important step towards the design of artificial catalysts that compete with natural enzymes. 


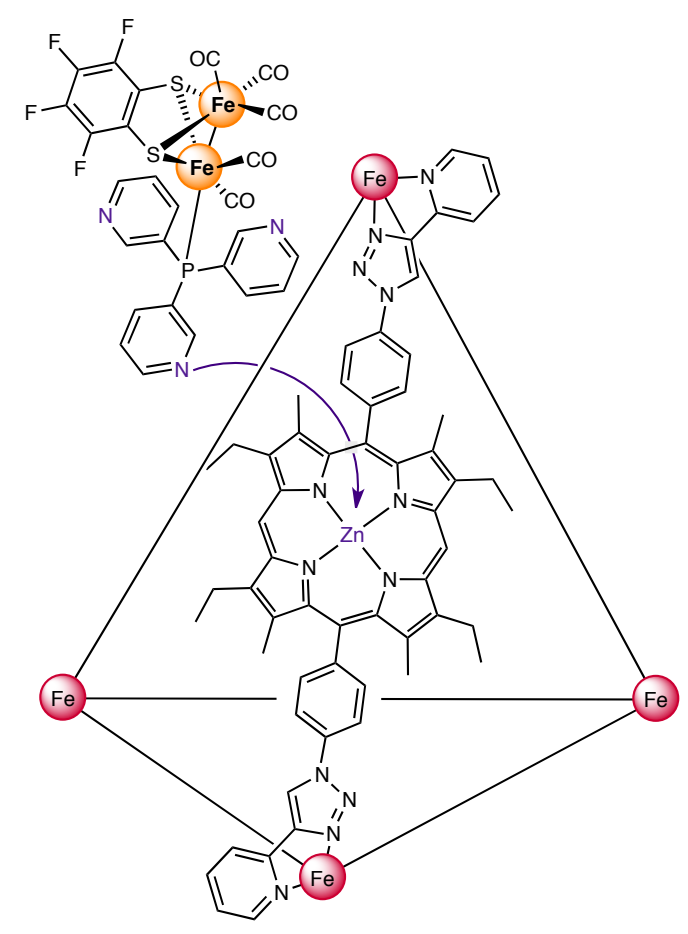

Scheme 33. An iron-based hydrogenase mimic (for proton reduction) featuring a tris(meta-pyridyl)phosphine ligand is encapsulated inside a zinc(II) porphyrin-based tetrahedral cage via $\mathrm{Zn} \cdots \mathrm{N}$ interactions.

Other types of ditopic ligands different than tris(metapyridyl)phosphine were developed. For instance, tris(parapyridyl)phosphine was revealed appropriate for its twofold encapsulation inside Nitschke's tetrahedral self-assembly made up from zinc-porphyrin derivatives via $\mathrm{Zn} \cdots \mathrm{N}$ coordination. ${ }^{157}$ The design enables the in situ formation of a hydroformylation rhodium catalyst that features substrate selectivity in which even-numbered olefins were more reactive than odd-numbered ones (Scheme 34). The same tetrahedral assembly was used to encapsulate an [FeFe] hydrogenase mimic containing a pyridylphosphole moiety via $\mathrm{Zn} \cdots \mathrm{N}$ coordination. ${ }^{158}$ The system was applied in the light-harvesting hydrogen evolution reaction, in which the zinc-porphyrins served as photosensitizers allowing electron transfer to the encapsulated iron catalyst upon excitation (Scheme 34). Secondary $\mathrm{Zn} \cdots \mathrm{N}$ coordination also drives the encapsulation of a chiral rhodium-coordinated phosphoramidite ligand inside Ribas's tetrahedral cage comprising zinc-porphyrins (Scheme 35). ${ }^{159}$ The corresponding catalyst exhibited one of the highest activities (up to 1600 TOF) and enantioselectivities (up to $79 \%$ $e e)$ for mono-ligated rhodium species in the hydroformylation of styrene derivatives. Overall, the above-described examples show the impact of the second coordination sphere in the catalysis, as the substrate can access only very selected geometrical conformations during the catalytic events.

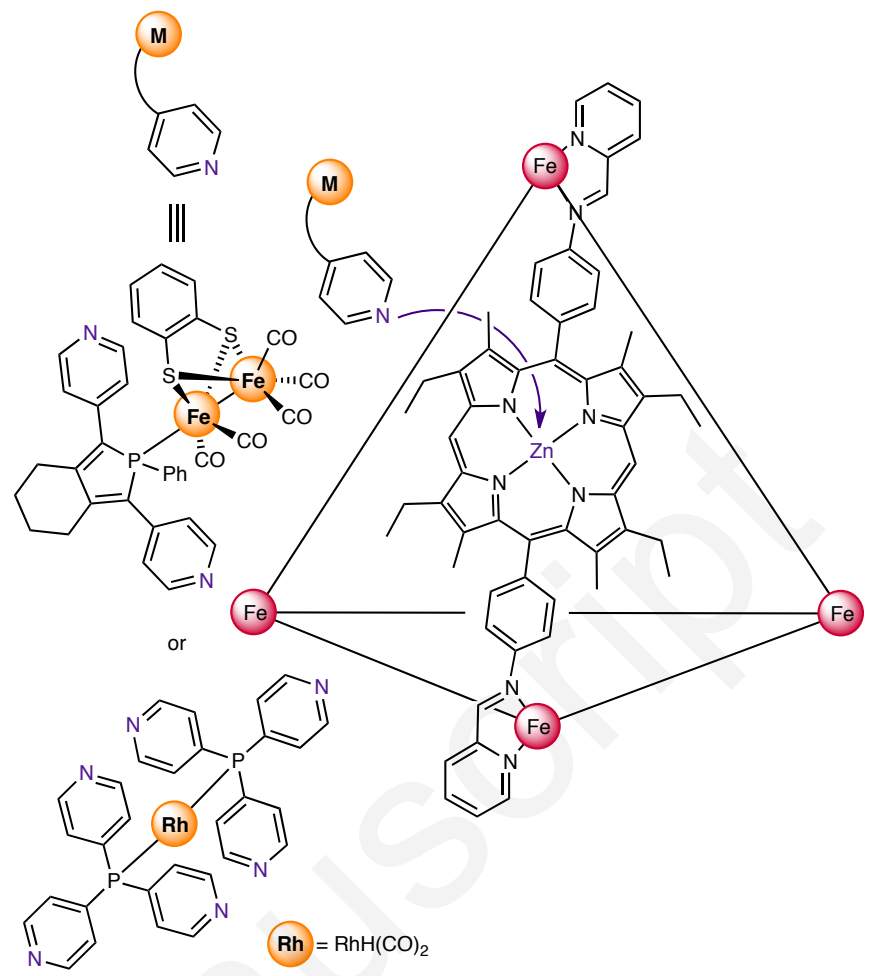

Scheme 34. An iron-based hydrogenase mimic (for proton reduction) featuring a bis(para-pyridyl)phosphole ligand and a tris(parapyridyl)phosphine-ligated rhodium catalyst (for hydroformylation) are confined in a zinc(II) porphyrin-based tetrahedral cage via $\mathrm{Zn} \cdots \mathrm{N}$ interactions. 

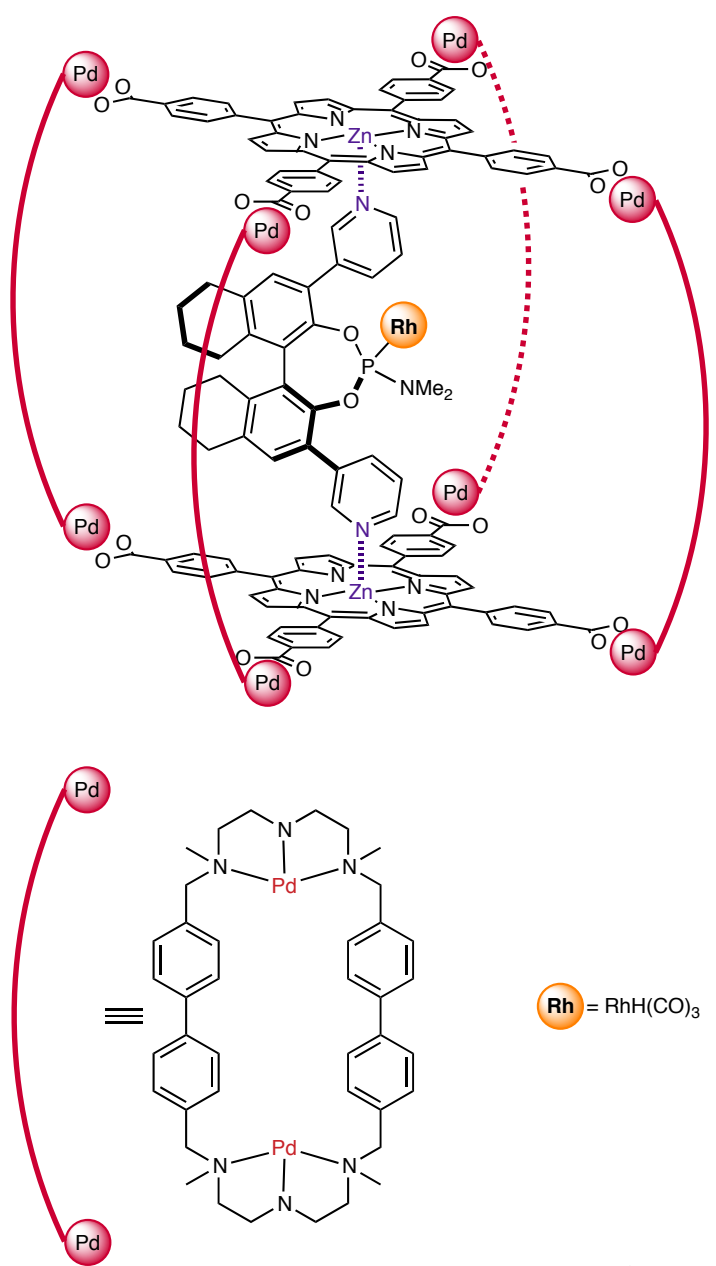

Scheme 35. A bis(meta-pyridyl)phosphoramidite-ligated rhodium catalyst (for hydroformylation) is confined in a zinc(II) porphyrin-based cage via $\mathrm{Zn} \cdots \mathrm{N}$ interactions.

\section{2. $\mathrm{Zn}{ }^{\cdots} \mathrm{N}$ coordination for substrate pre-organization.}

Alternatively to the previous approach, seminal contributions from the Sanders group revealed the reversible nature of
$\mathrm{Zn} \cdots \mathrm{N}$ coordination within dimers and trimers of zincporphyrins for accelerating and controlling product selectivity in organic Diels-Alder transformations. ${ }^{160-161}$ It was not until 2017 that this property was successfully utilized in transition metal catalysis. It was shown that the reactivity of chloro- and bromo-pyridines in palladium-catalyzed Suzuki and Heck was strongly affected by the presence of zinc-containing scaffolds in the reaction mixture. ${ }^{162}$ Increased reaction rates and reactivity were observed for those substrates able to interact with the zinc-containing scaffolds because they were involved in secondary $\mathrm{Zn} \cdots \mathrm{N}$ coordination whilst the palladium catalyst was operating. On the other hand, the substrates that did not interact with zinc-scaffolds led to catalyst deactivation by overcoordination of the substrate (or product) to the palladium centre. The catalytic activity of palladium was roughly correlated with the strength of the secondary $\mathrm{Zn} \cdots \mathrm{N}$ coordination, being higher with zinc-salphen than with zinctetraphenylporphyrin (Scheme 36, left). Such effect required, at least, one equivalent of zinc scaffold. A catalytic version was further developed customizing a zinc-tetraphenylporphyrin with four rigid nitrile groups in the periphery pointing to the porphyrin core. In this supramolecular ligand, there was space enough for pyridine derivatives to bind to the zinc centre via $\mathrm{Zn} \cdots \mathrm{N}$ coordination whereas the peripheral nitrile groups coordinate to the catalytically active palladium centre. ${ }^{163}$ In this manner, it was possible to perform substrate-selective catalysis for differentiating the reactivity between ortho-, meta- and para-bromopyridine in Suzuki-Miyaura coupling reactions. The supramolecular catalyst was fit perfectly for meta-bromopyridine (Scheme 36, right), a feature that was highlighted in competition experiments. Consequently, these studies established that the reversibility and dynamic nature of secondary $\mathrm{Zn} \cdots \mathrm{N}$ coordination are useful to design supramolecular catalysts to address reactivity issues arising from nitrogen-containing chemicals.

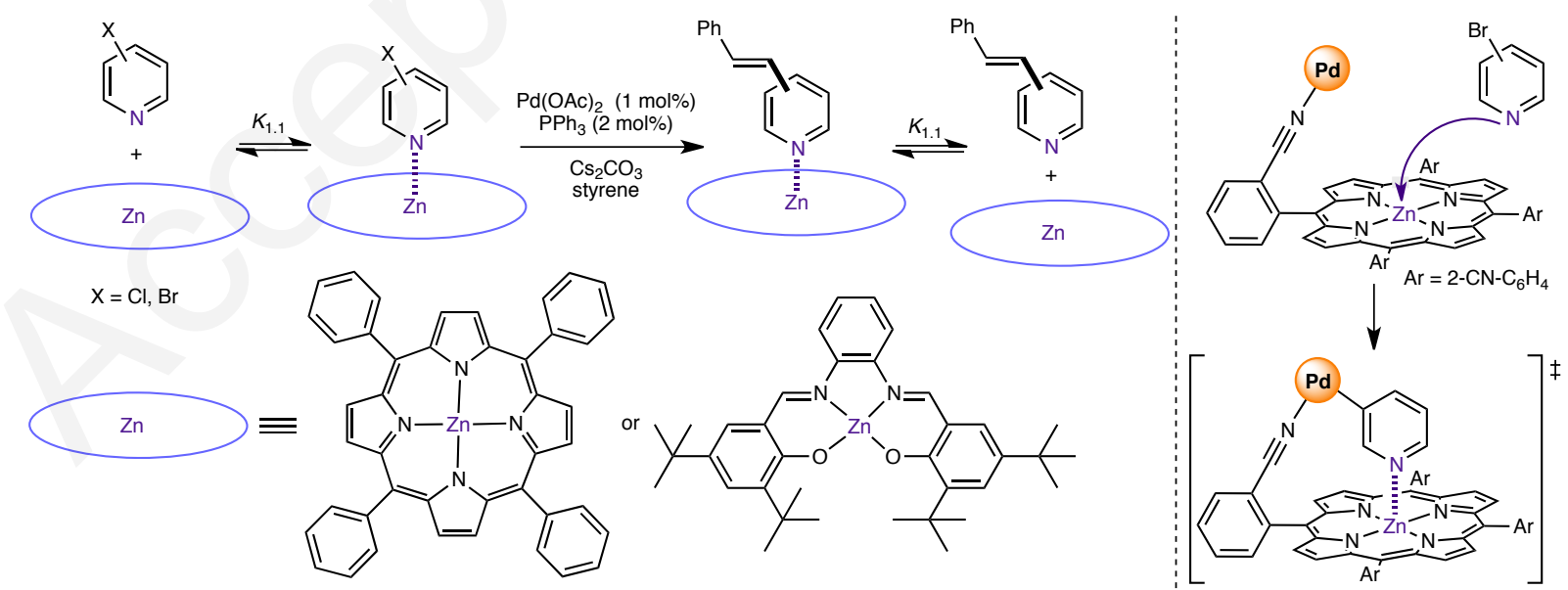

Scheme 36. The $\mathrm{Zn} \cdots \mathrm{N}$ coordination between the zinc(II)-porphyrin or zinc(II)-salphen with halopyridine substrates indirectly increase the lifetime of the palladium catalyst to perform a Heck reaction (left ) and a supramolecular palladium catalyst featuring a zinc(II) porphyrin as a substrate recognition site for halopyridine substrates (right). 


\section{3. $\mathrm{Pd}$ '”N coordination for substrate pre-organization.}

The group of $\mathrm{Yu}$ has pioneered the use of highly sophisticated and covalently-linked directing groups to position a palladium active catalyst far beyond the classical ortho-selectivity for aromatic $\mathrm{C}-\mathrm{H}$ bond functionalizations. ${ }^{164}$ It is relevant to note that transition metal-catalyzed distal $\mathrm{C}-\mathrm{H}$ bond activations are typically ensured by directing groups, which impose issues associated to the introduction and removal of the directing group, besides the extensive efforts devoted to trial-and-error screening to search for the optimal catalytic system. ${ }^{165-166}$ In 2017, the Yu group disclosed an approach based on so-called supramolecular templates that do not require the use of covalently-linked directing groups. These templates feature (1) a substrate recognition site based on a palladium-chelating unit and (2) a coordinating group based on nitriles or heterocyclic motifs to bind the active palladium catalyst. This design is particular useful for addressing difficult regioselective $\mathrm{C}-\mathrm{H}$ bond functionalizations of nitrogen-containing heterocycles. The substrate interacts with the recognition site via secondary $\mathrm{Pd} \cdots \mathrm{N}$ coordination, thus pre-disposing a remote $\mathrm{C}-\mathrm{H}$ bond at close proximity to the active palladium site. The distance and the geometry between both binding and catalytic sites are key parameters for the success of the catalysis (Scheme 37). For instance, this strategy was applied to palladium-catalyzed olefinations of $\mathrm{C}-\mathrm{H}$ bonds located at the meta-position of the phenyl group belonging to 3phenylpyridine derivatives under catalytic conditions. ${ }^{167} \mathrm{C}-\mathrm{H}$ bond olefination at the $\mathrm{C}-5$ position of quinoline derivatives was also demonstrated at the expenses of using stoichiometric amounts of the palladium template (Scheme 38 ). ${ }^{167}$
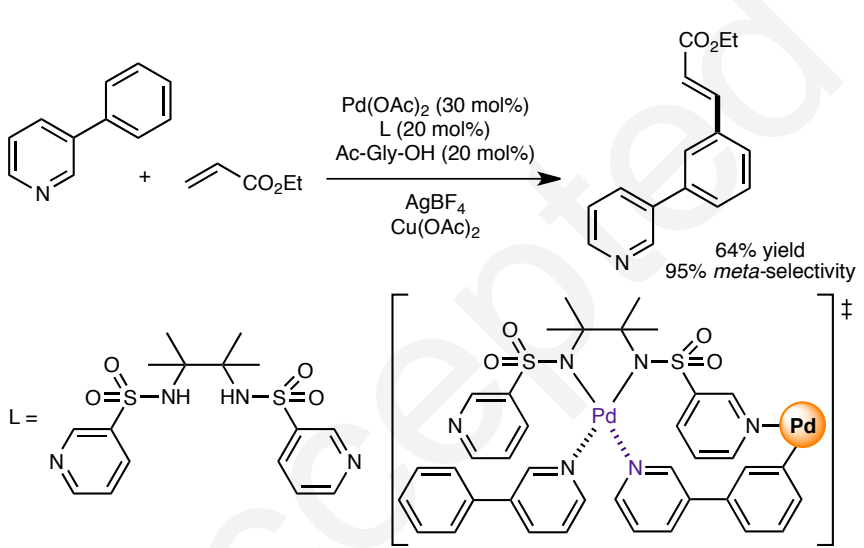

Scheme 37. The remote palladium-catalyzed $\mathrm{C}-\mathrm{H}$ bond olefination of 3phenylpyridines is possible owing to a supramolecular ligand containing a palladium fragment serving for substrate recognition via reversible $\mathrm{Pd} \cdots \mathrm{N}$ coordination.

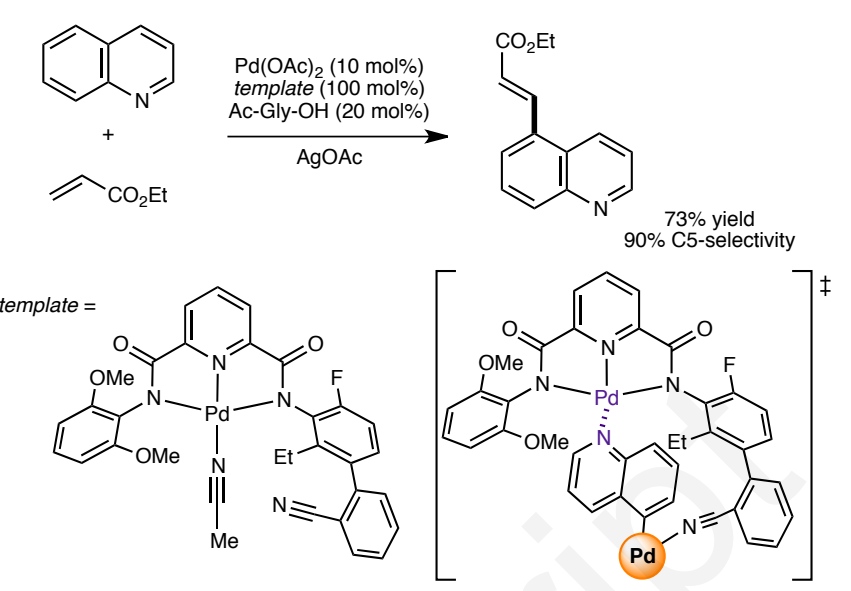

Scheme 38. Stoichiometric amounts of a $C_{1}$-symmetric palladium template enabled the palladium-catalyzed $\mathrm{C}-\mathrm{H}$ bond olefination of quinolines at the $\mathrm{C} 5$ position.

Such methodology was corroborated by Maiti's group using $C_{2}$-symmetric templates ${ }^{168}$ and further expanded to thiazole substrates (Scheme $\mathbf{3 9}$ ). ${ }^{\mathbf{1 6 9}}$ The same group employed allylic alcohols as coupling partners for the palladium-catalyzed $\mathrm{C}-\mathrm{H}$ bond alkylation at the $\mathrm{C}-5$ position of quinoline and thiazole derivatives, and at the $\mathrm{C}-7$ position for benzothiazole and benzoxazole, respectively. This time, the reaction was enabled by a $C_{1}$-symmetric template (Scheme 40). ${ }^{170}$ All these regio-selectivities cannot be achieved with ligands or templates lacking the well-designed recognition site within the second coordination sphere.
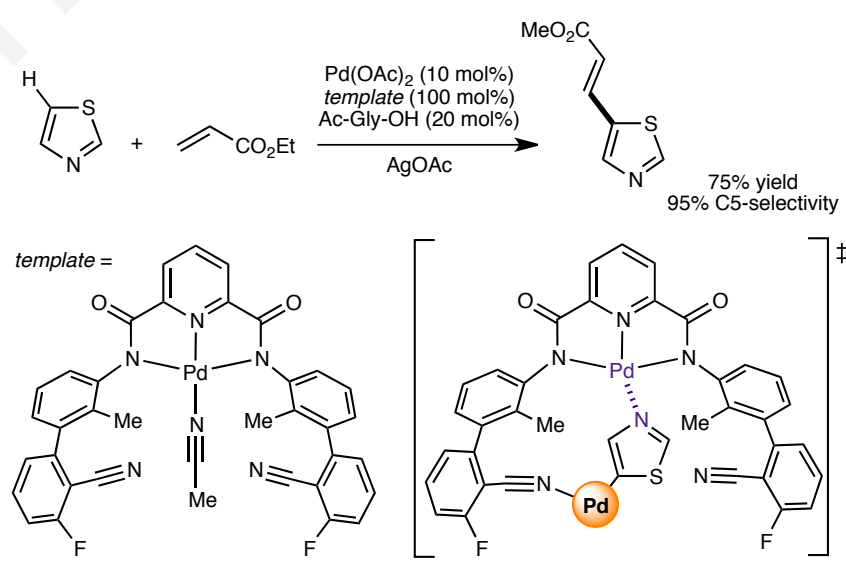

Scheme 39. A $C_{2}$-symmetric palladium template displayed C5selectivity for the palladium-catalyzed $\mathrm{C}-\mathrm{H}$ bond olefination of thiazoles. 


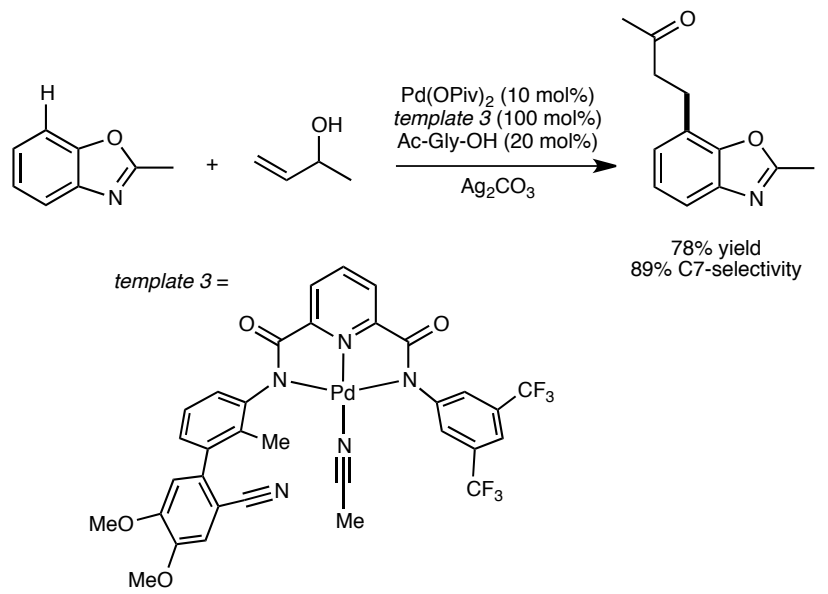

Such level of sophistication was upgraded by merging this template strategy with the Catellani reaction, which consists in employing a $\mathrm{Pd} /$ norbornene catalytic system to functionalize one $\mathrm{C}-\mathrm{H}$ bond away from the first $\mathrm{C}-\mathrm{H}$ bond activation. ${ }^{171}$ As a consequence, remote $\mathrm{C}-\mathrm{H}$ bond arylations of quinoline derivatives at the C-6 position were reached (Scheme 41). The exquisite control of regio-selectivity is astonishing as there are very little stereoelectronic differences between the C- 6 and C7 position within the quinoline skeleton.

Scheme 40. A $\mathrm{C}_{1}$-symmetric palladium template enabling distal $\mathrm{C}-\mathrm{H}$ bond selectivity for different heterocycles.

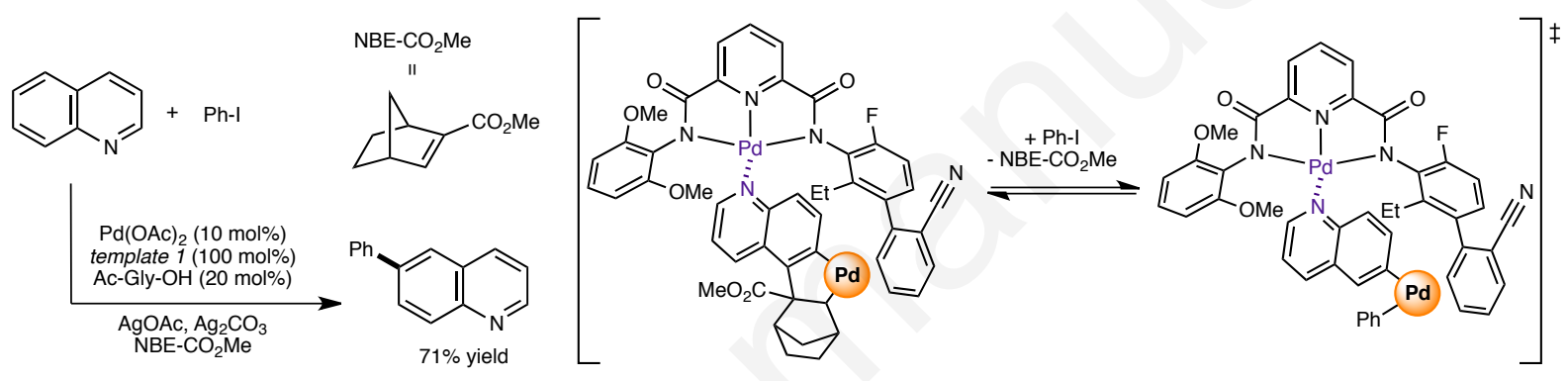

Scheme 41. The $\mathrm{C}-\mathrm{H}$ bond arylation at the $\mathrm{C} 6$ position of quinolines was addressed using a palladium template and a mediator (NBE- $\mathrm{CO}{ }_{2} \mathrm{Me}$ ) exploiting secondary $\mathrm{Pd} \cdots \mathrm{N}$ coordination.

Due to the almost irreversible nature of the $\mathrm{Pd} \cdots \mathrm{N}$ interaction, this approach requires the use of significant amounts of expensive and scarce palladium (>100 mol\% considering the template and the catalyst). Nevertheless, it provides access to regio-selectivities impossible to get with any other catalytic system to date. Furthermore, it is possible to recycle and recover the template by treatment with 4dimethylaminopyridine, which coordinates stronger to the palladium template than the substrates and the products, followed by a mild acidification. ${ }^{167-171}$ It is relevant to note that the success of these strategies relies also on the non-negligible roles of mono-protected amino acids co-ligands, silver salts and hexafluoroisopropanol as solvent.

\section{Conclusions and perspectives.}

In summary, the above-described range of secondary interactions smartly combined with transition metal catalysts are efficient tools to provide unprecedented possibilities to control activity and selectivity for organic transformations. These interactions are rather versatile. Indeed, they can be weak enough for substrate pre-organization in a reversible manner, or much stronger which make them relevant for the self-assembly of new ligand systems. The above-surveyed catalytic systems complement the traditional ones by increasing or reversing selectivities (i.e. site, regio, stereo, enantio, diastereo) as well as by accessing otherwise unfavoured products. New concepts, similar to those occurring in Nature, emerged from these systems. For example, some catalysts display size-, shape- or substrate-selectivity, which are difficult features to disclose with more classical homogeneous catalysts. In addition, several cases showcased high catalyst lifetime with notable turnover numbers and others displayed an in situ on/off control of reactivity, which are truly relevant for application purposes. Unfortunately, many examples still suffer from a detailed understanding of the strength of such interactions under catalytic conditions as well as kinetic studies that should help further rational developments. This knowledge might be useful for devising appropriate reaction conditions in which solvent properties and temperature are likely the most practical aspects for accessing the compatibility of the different components during the catalysis.

The majority of the supramolecular catalysts herein discussed are based on scarce second and third row late transition metals ( $\mathrm{Pd}, \mathrm{Rh}, \mathrm{Ir}, \mathrm{Ru}$, etc.). Therefore, it will be also convenient to turn the attention to more abundant and affordable first row transition metals that have recently shown 
interesting catalytic performances, ${ }^{172-173}$ in particular those derived from $\mathrm{Fe}, \mathrm{Cu}, \mathrm{Co}, \mathrm{Mn}$ and $\mathrm{Ni}$. On the other hand, it remains difficult to fully predict the action mode of these new catalysts which translates usually in significant efforts still devoted to trial-and-error screening to search for the optimal ones. In order to overcome this undesired consequence, incorporation of deconvolution strategies, ${ }^{174-175}$ highthroughput experimentation, ${ }^{\mathbf{1 7 6 - 1 7 7}}$ or exploiting dynamic combinatorial chemistry, ${ }^{\mathbf{1 7 8}}$ which are already well-established strategies in molecular catalysis, may play an important role in the future for this type of supramolecular catalysis. Furthermore, it will be interesting to disclose the first examples of homogeneous transition metal catalysis controlled by well-defined, secondary anion $\cdots \pi$ interactions, ${ }^{179}$ which are so far elusive to date although known for organocatalysis. ${ }^{\mathbf{1 8 0}}$ Additional interactions such as London, dispersion interactions or inductive effects, which could be considered more subtle and/or exotic interactions than the ones described in this review, may account for future developments, ${ }^{181-183}$ although they appear to remain extremely difficult to apply for prediction of catalytic outcomes. ${ }^{184}$ Taking into account the entire above-mentioned, one can only expect a bright future for transition metal catalysts controlled by secondary interactions beyond hydrogen bonding, and span the future possibilities of supramolecular catalysis.

\section{Conflicts of interest}

There are no conflicts to declare.

\section{Acknowledgements}

The CNRS, University of Rennes 1 and Agence Nationale de la Recherche (PhD fellowship to J.T.) are acknowledged for financial support.

\section{Notes and references}

1 Homogeneous catalysis. Understanding the art (ed. van Leeuwen, P. W. N. M., Springer, 2004).

2 Catalysis: from principles to applications (eds. Beller, M., Renken, A. \& van Santen R. A., Wiley-VCH, 2012).

3 Ligand design in metal chemistry: reactivity and catalysis (eds. Stradiotto, M. \& Lundgren, R. J., Wiley-VCH, 2016).

4 Organotransition metal chemistry. From bonding to catalysis (ed. Hartwig, J. F., University Science Books, 2010).

5 Phosphorus(III) ligands in homogeneous catalysis: design and synthesis (eds. Kamer, P. C. J. \& van Leeuwen, P. W. N. M., Wiley-VCH, 2012).

6 D. Ringe and G. A. Petsko, Science 2008, 320, 1428-1429.

7 From enzyme models to model enzymes (eds. Kirby, A. J. \& Hollfelder, F., RSC, 2009).

8 Supramolecular catalysis (ed. van Leeuwen, P. W. N. M., Wiley-VCH, 2008).

9 T.S. Koblenz, J. Wassenaar, and J. N. H. Reek, Chem. Soc. Rev. 2008, 37, 247-262.

10 D. M. Vriezema, M. Comellas Aragones, J. A. A. W. Elemans, J. L. M. Cornelissen, A. E. Rowand and R. J. M. Nolte, Chem. Rev. 2005, 105, 1445-1489.
11 H. Amouri, C. Desmarets and J. Moussa, Chem. Rev. 2012, 112, 2015-2041.

12 M. Yoshizawa, J. K. Klosterman and M. Fujita, Angew. Chem. Int. Ed. 2009, 48, 3418-3438.

13 D. Fiedler, D. H. Leung, R. G. Bergman and K. N. Raymond, Acc. Chem. Res. 2005, 38, 349-358.

14 M. J. Wiester, P. A. Ulmann, and C. A. Mirkin, Angew. Chem. Int. Ed. 2011, 50, 114-137.

15 I. Nath, J. Chakraborty and F. Verpoort, Chem. Soc. Rev. 2016, 45, 4127-4170.

16 T. R. Cook, Y.-R. Zheng and P. J. Stang, Chem. Rev. 2013, 113, 734-777.

17 M. Raynal, P. Ballester, A. Vidal-Ferran and P. W. N. M. van Leeuwen, Chem. Soc. Rev. 2014, 43, 1734-1787.

18 Z. Dong, Q. Luo and J. Liu, Chem. Soc. Rev. 2012, 41, 78907908.

19 J. Meeuwissen and J. N. H. Reek, Nat. Chem. 2010, 2, 615621.

20 K. T. Mahmudov, A. V. Gurbanov, F. I. Guseinov, M. F. Guedes da Silva, Coord. Chem. Rev. 2019, 387, 32-46.

21 B. Breit, Angew. Chem. Int. Ed. 2005, 44, 6816-6825.

22 S. Carboni, C. Gennari, L. Pignataro and U. Piarulli, Dalton Trans. 2011, 40, 4355-4373.

23 P. Dydio and J. N. H. Reek, Chem. Sci. 2014, 5, 2135-2145.

24 M. Raynal, P. Ballester, A. Vidal-Ferran and P. W. N. M. van Leeuwen, Chem. Soc. Rev. 2014, 43, 1660-1733.

25 H. J. Davis and R. J. Phipps, Chem. Sci. 2017, 8, 864-877.

26 M. R. Mote, S. H. Chikkali, Chem. Asian J. 2018, 13, 36233646.

27 R. Noyori, Nat. Chem. 2009, 1, 5-6.

28 A. J. Esswein and D. G. Nocera, Chem. Rev. 2007, 107, 40224047.

29 R. L. Shook and A. S. Borovik, Inorg. Chem. 2010, 49, 36463660.

30 M. Zhao, H.-B. Wang, L.-N. Ji and Z.-W. Mao, Chem. Soc. Rev. 2013, 42, 8360-8375.

31 S. A. Cook and A. S. Borovik, Acc. Chem. Res. 2015, 48, 24072414.

32 S. E. Creutz and J. C. Peters, Chem. Sci. 2017, 8, 2321-2328.

33 M. L. Pegis, C. F. Wise, D. J. Martin and J. N. Mayer, Chem. Rev. 2018, 118, 2340-2391.

34 M. A. Ehudin, A. W. Schaefer, S. M. Adam, D. A. Quist, D. E. Diaz, J. A. Tang, E. I. Solomon and K. D. Karlin, Chem. Sci. 2019, 10, 2893-2905.

35 A. Warshel, P. K. Sharma, M. Kato, Y. Xiang, H. Liu and M. H. M. Olsson, Chem. Rev. 2006, 106, 3210-3235.

36 G. G. Hammes, S. J. Benkovic and S. Hammes-Schiffer, Biochemistry 2011, 50, 10422-10430.

37 K. Ohmatsu and T. Ooi, Topics Curr. Chem. 2019, 377, 31

38 K. Ohmatsu, N. Imagawa and T. Ooi, Nat. Chem. 2014, 6, 4751.

39 K. Ohmatsu, S. Kawai, N. Imagawa and T. Ooi, ACS Catal. 2014, 4, 4304-4306.

40 C. Chen, H. Wang, Z. Zhang, S. Jin, S. Wen, J. Ji, L. W. Chung, X.-Q. Dong and X. Zhang, Chem. Sci. 2016, 7, 6669-6673.

41 S. Wen, C. Chen, S. Du, Z. Zhang, Y. Huang, Z. Han, X.-Q. Dong and X. Zhang, Org. Lett. 2017, 19, 6474-6477.

$42 \mathrm{X}$. Yin, C. Chen, X. Li, X.-Q. Dong and X. Zhang, Org. Lett. 2017, 19, 4375-4378.

43 Q. Zhao, J. Wen, R. Tan, K. Huang, P. Metola, R. Wang, E. V. Anslyn and X. Zhang, Angew. Chem. Int. Ed. 2014, 53, 84678470.

44 J. Wen, R. Tan, S. Liu, Q. Zhao and X. Zhang, Chem. Sci. 2016 , 7, 3047-3051.

45 J. Wen, X. Fan, R. Tan, H.-C. Chien, Q. Zhou, L. W. Chung and X. Zhang, Org. Lett. 2018, 20, 2143-2147.

46 T. Yang, Y. Sun, H. Wang, Z. Lin, J. Wen and X. Zhang, Angew. Chem. Int. Ed. 2020, 59, 6108-6114. 
47 H. J. Davis, M. T. Mihai and R. J. Phipps, J. Am. Chem. Soc. 2016, 138, 12759-12762.

48 M. T. Mihai, H. J. Davis, G. R. Genov and R. J. Phipps, ACS Catal. 2018, 8, 3764-3769.

49 B. Lee, M. T. Mihai, V. Stojalnikova and R. J. Phipps, J. Org. Chem. 2019, 84, 13124-13134.

50 M. T. Mihai, B. D. Williams and R. J. Phipps, J. Am. Chem. Soc. 2019, 141, 15477-15482.

51 J. R. Montero Bastidas, T. J. Oleskey, S. L. Miller, M. R. Smith, III and R. E. Maleczka, Jr, J. Am. Chem. Soc. 2019, 141, 15483-15487.

52 W. A. Golding, R. Pearce-Higgins and R. J. Phipps, J. Am. Chem. Soc. 2018, 140, 13570-13574.

53 W. A. Golding and R. J. Phipps, Chem. Sci. 2020, 11, 30223027.

54 M. E. Hoque, R. Bisht, C. Haldar and B. Chattopadhyay, J. Am. Chem. Soc. 2017, 139, 7745-7748.

55 R. Bisht, M. E. Hoque and B. Chattopadhyay, Angew. Chem. Int. Ed. 2018, 57, 15762-15766.

56 Q. Lu, H. Yu and Y. Fu, J. Am. Chem. Soc. 2014, 136, 82528260.

57 H. Xu, K. Muto, J. Yamaguchi, C. Zhao, K. Itami, and D. G. Musaev, J. Am. Chem. Soc. 2014, 136, 14834-14844.

58 B. E. Haines and D. G. Musaev, ACS Catal. 2015, 5, 830-840.

59 K. Muto, K. Yamaguchi, D. G. Musaev, and K. Itami, Nat. Commun. 2015, 6, 7508.

60 J. Jiang, J.-Q. Yu and K. Morokuma, ACS Catal. 2015, 5, 36483661.

61 Y. Zhou and X. Bao, Org. Lett. 2016, 18, 4506-4509.

62 B. E. Haines, J. F. Berry, J.-Q. Yu and D. G. Musaev, ACS Catal. 2016, 6, 829-839.

63 M. Anand, R. B. Sunoj and H. F. Schaefer, III, ACS Catal. 2016, 6, 696-708.

64 A. L. Dewyer and P. M. Zimmerman, ACS Catal. 2017, 7, 5466-5477.

65 M. C. D’Alterio, Y.-C. Yuan, C. Bruneau, G. Talarico, R. Gramage-Doria and A. Poater, Catal. Sci. Technol. 2020, 10, $180-186$.

66 X. Jin, H. Xu, N. Zhao, R. Li, and Y. Dang, Org. Lett. 2020, 22 $1464-1468$.

67 K. Ohmatsu, M. Ito, T. Kunieda and T. Ooi, Nat. Chem. 2012, 4, 473-477.

68 K. Ohmatsu, M. Ito and T. Ooi, Chem. Commun. 2014, 50, 4554-4557.

69 K. Ohmatsu, Y. Hara and T. Ooi, Chem. Sci. 2014, 5, 36453650.

70 Y. Hara, Y. Kusano, K. Ohmatsu and T. \& Ooi, Chem. Lett. 2016, 45, 552-554.

71 G. R. Genov, J. L. Douthwaite, A. S. K. Lahdenperä, D. C. Gibson and R. J. Phipps, Science 2020, 367, 1246-1251.

72 H. J. Davis, G. R. Genov and R. J. Phipps, Angew. Chem. Int. Ed. 2017, 56, 13351-13355.

73 S. Dana, D. Chowdhury, A. Mandal, F. A. S. Chipem and M. Baidya, ACS Catal. 2018, 8, 10173-10179.

74 Q.-Q. Wang, S. Gonell, S. H. A. M. Leenders, M. Dürr, I. Ivanović-Burmazović and J. N. H. Reek, Nat. Chem. 2016, 8, 225-230.

75 S. Gonell and J. N. H. Reek, ChemCatChem 2019, 11, 14581464.

76 S. Gonell, X. Caumes, N. Orth, I. Ivanović-Burmazović and J. N. H. Reek, Chem. Sci. 2019, 10, 1316-1321.

77 C. J. Pedersen, J. Am. Chem. Soc. 1967, 89, 2495-2496.

78 C. J. Pedersen, J. Am. Chem. Soc. 1967, 89, 7017-7036.

79 G. W. Gokel, D. M. Goli, C. Minganti and L. Echegoyen, J. Am. Chem. Soc. 1983, 105, 6786-6788.

80 M. Vaquero, L. Rovira, and A. Vidal-Ferran, Chem. Commun. 2016, 52, 11038-11051.

81 A. J. M. Miller, Dalton Trans. 2017, 46, 11987-12000.
82 C. Yoo, H. M. Dodge and A. J. M. Miller, Chem. Commun. 2019, 55, 5047-5059.

83 Y. Li, B. Ma, Y. He, F. Zhang, and Q.-H. Fan, Chem. Asian J. $2010,5,2454-2458$

84 I. Mon, D. A. Jose and A. Vidal-Ferran, Chem. Eur. J. 2013, 19, $2720-2725$.

85 A. Vidal-Ferran, I. Mon, A. Bauzá, A. Frontera and L. Rovira, Chem. Eur. J. 2015, 21, 11417-11426.

86 L. Rovira, M. Vaquero and A. Vidal-Ferran, J. Org. Chem. 2015, 80, 10397-10403.

87 L. Rovira, H. Fernández-Pérez and A. Vidal-Ferran, Organometallics 2016, 35, 528-533.

88 E. Iniesta and A. Vidal-Ferran, Chem. Commun. 2020, 56, 6364-6367.

89 L. Carreras, A. Franconetti, A. Grabulosa, A. Frontera and A. Vidal-Ferran, Org. Chem. Front. 2020, 7, 1626-1634.

90 L. Kovbasyuk and R. Krämer, Chem. Rev. 2004, 104, 3161-3188.

91 X.-C. Zhang, Y.-H. Hu, C.-F. Chen, Q. Fang, L.-Y. Yang, Y.-B. Lu, L.-J. Xie, J. Wu, S. Li and W. Fang, Chem. Sci. 2016, 7, 45944599.

92 G.-H. Ouyang, Y.-M. He and Q.-H. Fan, Chem. Eur. J. 2014, 20, 16454-16457.

93 E. N. Jacobsen, Acc. Chem. Res. 2000, 33, 421-431.

94 G.-H. Ouyang, Y.-M. He, Y. Li, J.-F. Xiang and Q.-H. Fan, Angew. Chem. Int. Ed. 2015, 54, 4334-4337.

95 M. Sawamura and Y. Ito, Chem. Rev. 1992, 92, 857-871.

96 G. Olivo, G. Farinelli, A. Barbieri, O. Lanzalunga, S. Di Stefano, M. Costas, Angew. Chem. Int. Ed. 2017, 56, 16347-16351.

97 G. Olivo, G. Capocasa, O. Lanzalunga, S. Di Stefano and M. Costas, Chem. Commun. 2019, 55, 917-920.

98 G. Olivo, G. Capocasa, B. Ticconi, O. Lanzalunga, S. Di Stefano and M. Costas, Angew. Chem. Int. Ed. 2020, 59, 1270312708.

99 A. J. Neel, M. J. Hilton, M. S. Sigman and F. D. Toste, Nature 2017, 543, 637-646.

100 M. Yamakawa, I. Yamada and R. Noyori, Angew. Chem. Int. Ed. 2001, 40, 2818-2821.

101 A. Sakakura, M. Hori, M. Fushimi and K. Ishihara, J. Am. Chem. Soc. 2010, 132, 15550-15552.

102 W. Xie, J. Heo, D. Kim and S. Chang, J. Am. Chem. Soc. 2020, 142, 7487-7496.

103 H.-Y. Luo, J.-W. Dong, Y.-Y. Xie, X.-F. Song, D. Zhu, T. Ding, Y. Liu and Z.-M. Chen, Chem. Eur. J. 2019, 25, 15411-15418.

104 Z.-M. Chen, J. Liu, J.-Y. Guo, M. Loch, R. J. DeLuca and M. S. Sigman, Chem. Sci. 2019, 10, 7246-7250.

105 M. A. B. Ferreira, J. De Jesus Silva, S. Grosslight, A. Fedorov, M. S. Sigman and C. Copéret, J. Am. Chem. Soc. 2019, 141, 10788-10800.

106 R. Huber, A. Passera, E. Gubler and A. Mezzetti, Adv. Synth. Catal. 2018, 360, 2900-2913.

107 A. Passera and A. Mezzetti Adv. Synth. Catal. 2019, 361 , 4691-4706.

108 A. Passera and A. Mezzetti, Angew. Chem. Int. Ed. 2020, 59, 187-191.

109 T. Korenaga, R. Sasaki, T. Takemoto, T. Yasuda and M. Watanabe, Adv. Synth. Catal. 2018, 360, 322-333.

110 M. Orlandi, M. J. Hilton, E. Yamamoto, F. D. Toste and M. S. Sigman, J. Am. Chem. Soc. 2017, 139, 12688-12695.

111 Y. Reddi, C.-C. Tsai, C. M. Avila, F. D. Toste and R. B. Sunoj, J. Am. Chem. Soc. 2019, 141, 998-1009.

112 S. Tribedi, C. M. Hadad and R. B. Sunoj, Chem. Sci. 2018, 9, 6126-6133.

113 P. M. Holstein, M. Vogler, P. Larini, G.Pilet, E. Clot and O. Baudoin, ACS Catal. 2015, 5, 4300-4308.

114 M. Huang, T. Yang, J. D. Paretsky, J. F. Berry and J. M. Schomaker, J. Am. Chem. Soc. 2017, 139, 17376-17386. 
115 H. Jung, M. Schrader, D. Kim, M.-H. Baik, Y. Park and S. Chang, J. Am. Chem. Soc. 2019, 141, 15356-15366.

116 R. L. Reyes, M. Sato, T. Iwai, K. Suzuki, S. Maeda and M. Sawamura, Science 2020, 369, 970-974.

117 R. L. Reyes, T. Iwai, S. Maeda and M. Sawamura, J. Am. Chem. Soc. 2019, 141, 6817-6821.

118 C. R. Kennedy, S. Lin and E. N. Jacobsen, Angew. Chem. Int. Ed. 2016, 55, 12596-12624.

119 S. Yamada, Chem. Rev. 2018, 118, 11353-11432.

120 D. A. Dougherty, Acc. Chem. Res. 2013, 46, 885-893.

121 S.-C. Sha, S. Tcyrulnikov, M. Li, B. Hu, Y. Fu, M. C. Kozlowski and P. J. Walsh, J. Am. Chem. Soc. 2018, 140, 12415-12423.

122 H. Jiang, S.-C. Sha, S. A. Jeong, B. C. Manor and P. J. Walsh, Org. Lett. 2019, 21, 1735-1739.

123 D. G. Musaev, T. M. Figg and A. L. Kaledin, Chem. Soc. Rev. 2014, 43, 5009-5031.

124 T. M. Figg, M. Wasa, J.-Q. Yu and D. G. Musaev, J. Am. Chem. Soc. 2013, 135, 14206-14214.

125 H.-R. Tong, S. Zheng, X. Li, Z. Deng, H. Wang, G. He, Q. Peng and G. Chen, ACS Catal. 2018, 8, 11502-11512.

126 B. E. Haines, X. Xu, P. Verma, X.-C. Wang, J.-Q. Yu and D. G. Musaev, J. Am. Chem. Soc. 2015, 137, 9022-9031.

127 M. C. Schwarzer, R. Konno, T. Hojo, A. Ohtsuki, K. Nakamura, A. Yasutome, H. Takahashi, T. Shimasaki, M. Tobisu, N. Chatani and S. Mori, J. Am. Chem. Soc. 2017, 139, 10347-10358.

128 B. Kim, A. J. Chinn, D. R. Fandrick, C. H. Senanayake, R. A. Singer and S. J. Miller, J. Am. Chem. Soc. 2016, 138, 79397945.

129 A. J. Chinn, B. Kim, Y. Kwon and S. J. Miller, J. Am. Chem Soc. 2017, 139, 18107-18114.

130 G. Lian, Y. Ji, H. Liu, Y. Pang, B. Zhou, M. Cheng, Y. Liu, B. Lin and Y. Liu, Adv. Synth. Catal. 2020, 362, 192-205.

131 D. Bulfield and S. M. Huber, Chem. Eur. J. 2016, 22 14434-14450.

132 R. L. Sutar and S. M. Huber, ACS Catal. 2019, 9, 96229639.

133 V. N. G. Lindsay, W. Lin and A. B. Charette, J. Am. Chem. Soc. 2009, 131, 16383-16385.

134 V. N. G. Lindsay and A. B. Charette, ACS Catal. 2012, 2, 1221-1225.

135 L. Carreras, M. Serrano-Torne, P. W. N. M. van Leeuwen and A. Vidal-Ferran, Chem. Sci. 2018, 9, 3644-3648.

136 L. Carreras, J. Benet-Buchholz, A. Franconetti, A. Frontera, P. W. N. M. van Leeuwen and A. Vidal-Ferran, Chem. Commun. 2019, 55, 2380-2383.

137 K. Guillier, E. Caytan, V. Dorcet, F. Mongin, E. Dumont and F. Chevallier, Angew. Chem. Int. Ed. 2019, 58, 1494014943.

138 T. Caronna, R. Liantonio, T. A. Logothetis, P. Metrangolo, T. Pilati and G. Resnati, J. Am. Chem. Soc. 2004, 126, 45004501.

139 T. Arai, K. Horigane, O. Watanabe, J. Kakino, N. Sugiyama, H. Makino, Y. Kamei, S. Yabe and M. Yamanaka, iScience 2019, 12, 280-292.

140 S. Iwase, Y. Suzuki, S. Tanaka and M. Kitamura, Org. Lett. 2020, 22, 1929-1933.

141 S. E. Denmark and G. L. Beutner, Angew. Chem. Int. Ed. 2008, 47, 1560-1638.

142 J. Becica and G. E. Dobereiner, Org. Biomol. Chem. 2019, 17, 2055-2069.

143 H. L. Li, Y. Kuninobu and M. Kanai, Angew. Chem. Int. Ed. 2017, 56, 1495-1499.

144 L. Yang, N. Uemura and Y. Nakao, J. Am. Chem. Soc. 2019, 141, 7972-7979.

145 L. Yang, K. Semba and Y. Nakao, Angew. Chem. Int. Ed. 2017, 56, 4853-4857.
146 R. Bisht and B. Chattopadhyay, J. Am. Chem. Soc. 2016 $138,84-87$

147 H.-L. Li, M. Kanai and Y. Kuninobu, Org. Lett. 2017, 19, 5944-5947.

148 I. Beletskaya, V. S. Tyurin, A. Y. Tsivadze, R. Guilard and C. Stern, Chem. Rev. 2009, 109, 1659-1713.

149 Y. Nakamura, N. Aratani and A. Osuka, Chem. Soc. Rev. 2007, 36, 831-845.

150 V. F. Slagt, J. N. H. Reek, P. C. J. Kamer and P. W. N. M. van Leeuwen, Angew. Chem. Int. Ed. 2001, 40, 4271-4274.

151 L. J. Jongkind, X. Caumes, A. P. T. Hartendorp and J. N. H. Reek, Acc. Chem. Res. 2018, 51, 2115-2128.

152 X. Wang, S. S. Nurttila, W. I. Dzik, R. Becker, J. Rodgers and J. N. H. Reek, Chem. Eur. J. 2017, 23, 14769-14777.

153 L. J. Jongkind and J. N. H. Reek, Chem. Asian. J. 2020, 15 867-875.

154 L. J. Jongkind, J. A. A. W. Elemans and J. N. H. Reek, Angew. Chem. Int. Ed. 2019, 58, 2696-2699.

155 J. A. A. W. Elemans, M. B. Claase, P. P. M. Aarts, A. E. Rowan, A. P. H. J. Schenning and R. J. M. Nolte, J. Org. Chem. 1999, 64, 7009-7016.

156 S. S. Nurttila, R. Zaffaroni, S. Mathew and J. N. H. Reek, Chem. Commun. 2019, 55, 3081-3084.

157 S. S. Nurttila, W. Brenner, J. Mosquera, K. M. van Vliet, J. R. Nitschke and J. N. H. Reek, Chem. Eur. J. 2019, 25, 609620.

158 S. S. Nurttila, R. Becker, J. Hessels, S. Woutersen and J. N. H. Reek, Chem. Eur. J. 2018, 24, 16395-16406.

159 C. García-Simón, R. Gramage-Doria, S. Raoufmoghaddam, T. Parella, M. Costas, X. Ribas and J. N. H. Reek, J. Am. Chem. Soc. 2015, 137, 2680-2687.

160 M. Marty, Z. Clyde-Watson, L. J. Twyman, M. Nakash and J. K. M. Sanders, Chem. Commun. 1998, 2265-2266.

161 M. Nakash, Z. Clyde-Watson, N. Feeder, J. E. Davies, S. J. Teat and J. K. M. Sanders, J. Am. Chem. Soc. 2000, 122, 5286-5293.

162 M. Kadri, J. Hou, V. Dorcet, T. Roisnel, L. Bechki, A. Miloudi, C. Bruneau and R. Gramage-Doria, Chem. Eur. J. 2017, 23, 5033-5043.

163 P. Zardi, T. Roisnel and R. Gramage-Doria, Chem. Eur. J. 2019, 25, 627-634.

164 G. Meng, N. Y. S. Lam, E. L. Lucas, T. G. Saint-Denis, P. Verma, N. Chekshin and J.-Q. Yu, J. Am. Chem. Soc. 2020, 142, 10571-10591.

165 F. F. Khan, S. K. Sinha, G. K. Lahiri and D. Maiti, Chem. Asian J. 2018, 13, 2243-2256.

166 C. Sambiagio, D. Schonbauer, R. Blieck, T. Dao-Huy, G. Pototschnig, P. Schaaf, T. Wiesinger, M. F. Zia, J. WencelDelord, T. Besset, B. U. W. Maes and M. Schnurch, Chem. Soc. Rev. 2018, 47, 6603-6743.

167 Z. Zhang, K. Tanaka and J.-Q. Yu, Nature 2017, 543, 538542.

168 T. K. Achar, K. Ramakrishna, T. Pal, S. Porey, P. Dolui, J. P. Biswas and D. Maiti, Chem. Eur. J. 2018, 24, 17906-17910.

169 T. K. Achar, J. P. Biswas, S. Porey, T. Pal, K. Ramakrishna, S. Maiti and D. Maiti, J. Org. Chem. 2019, 84, 8315-8321.

170 K. Ramakrishna, J. P. Biswas, S. Jana, T. K. Achar, S. Porey and D. Maiti, Angew. Chem. Int. Ed. 2019, 58, 13808-13812.

171 H. Shi, Y. Lu, J. Weng, K. L. Bay, X. Chen, K. Tanaka, P. Verna and K. N. Houk, J.-Q. Yu, Nat. Chem. 2020, 12, 399404.

172 M. Beller, Chem. Rev. 2019, 119, 2089.

173 P. Chirik and R. Morris, Acc. Chem. Res. 2015, 48, 2495.

174 J. Wieland and B. Breit, Nat. Chem. 2010, 2, 832-837.

175 K. D. Collins, T. Gensch and F. Glorius, Nat. Chem. 2014, 6, 859-871.

176 D. W. Robbins and J. F. Hartwig, Science 2011, 333, 14231427. 
177 K. Troshin and J. F. Hartwig, Science 2017, 357, 175-181.

178 P. T. Corbett, J. Leclaire, L. Vial, K. R. West, J.-L. Wietor, J. K. M. Sanders and S. Otto, Chem. Rev. 2006, 106, 3652-3711.

179 M. Giese, M. Albrecht and K. Rissanen, Chem. Rev. 2015, 115, 8867-8895.

180 Y. Zhao, Y. Cotelle, L. Liu, J. López-Andarias, A.-B. Bornhof, M. Akamatsu, N. Sakai and S. Matile, Acc. Chem. Res. 2018, 51, 2255-2263.

181 A. A. Thomas, K. Speck, I. Kevlishvili, Z. Lu, P. Liu and S. L. Buchwald, J. Am. Chem. Soc. 2018, 140, 13976-13984.

182 P. Petrovic, J.-P. Djukic, A. Hansen, C. Bannwarth and S. Grimme, Non-covalent Interactions in the Synthesis and Design of New Compounds (ed. A. M. Maharramov, K. T. Mahmudov, M. N. Kopylovich and A. J. L. Pombeiro) 115-143 (Wiley-VCH, 2016).

183 L. Deng, Y. Fu, S. Y. Lee, C. Wang, P. Liu and G. Dong, J. Am. Chem. Soc. 2019, 141, 16260-16265.

184 M. Foscato and V. R. Jensen, ACS Catal. 2020, 10, 23542377. 
TOC

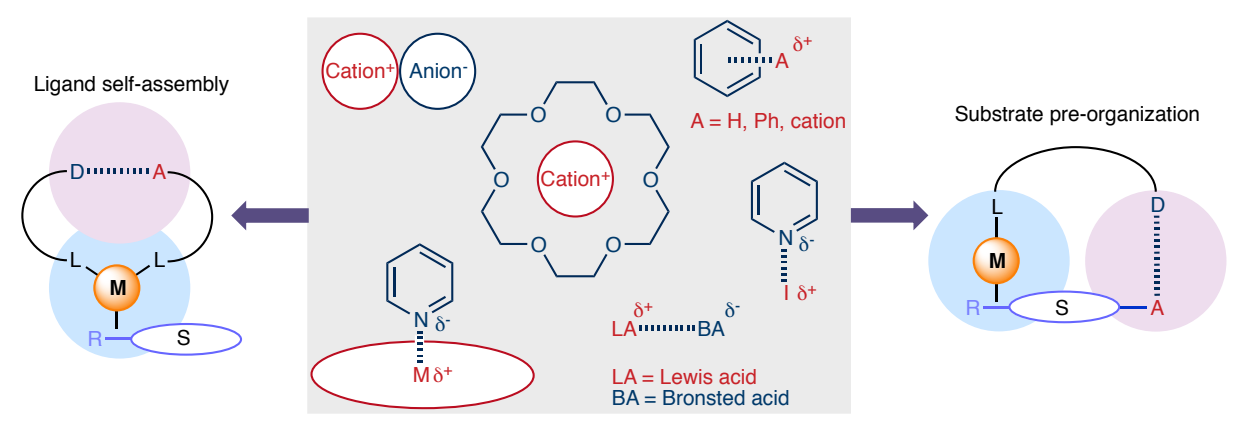

The implementation of interactions beyond hydrogen bonding in the $2^{\text {nd }}$ coordination sphere of transition metal homogeneous catalysts is rare. However, it has already shown great promise in the last five years providing unprecedented tools to control the activity and selectivity as it is herein discussed.

\section{Biographies}

Jonathan Trouvé obtained his MSc in Organic Chemistry from the University of Caen (France) in 2019 under the supervision of Dr. Bénédicte Lepoittevin and Dr. Jerôme Baudoux with a research project on zwitterionic polymers. Currently, he is pursuing his PhD under the supervision of Dr. Rafael Gramage-Doria in the University of Rennes (France) focusing on supramolecular and bio-inspired transition metal catalysis.

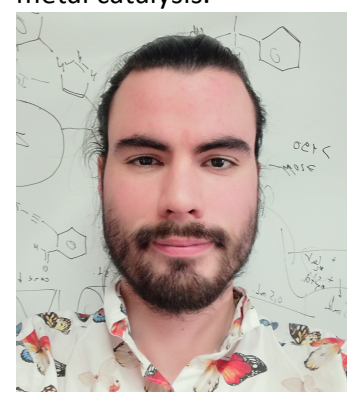

Rafael Gramage-Doria received his PhD from the University of Strasbourg (France) with Dr. Dominique Matt and Prof. Dominique Armspach. After a postdoctoral fellowship with Prof. Joost N. H. Reek at the University of Amsterdam (Netherlands) and later, with Prof. Takashi Ooi at Nagoya University (Japan), he joined in 2015 the Institute of Chemical Sciences of the University of Rennes (France) as a CNRS researcher where he obtained his Habilitation diploma (2019). His research activities include transition metal catalysis for fine chemicals and green chemistry applications, $\mathrm{C}-\mathrm{H}$ bond functionalization, supramolecular and coordination chemistry, and supramolecular and bio-inspired catalysis.

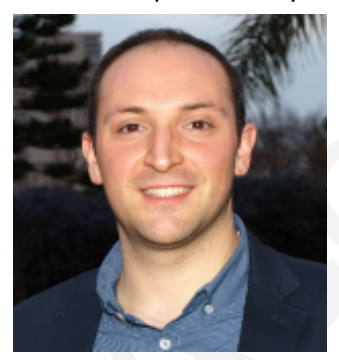

